Dipingere a Roma al tempo di Pasquale I: S. Prassede all'Esquilino e S. Cecilia in Trastevere ${ }^{1}$

\title{
Giulia Bordi
}

Università degli Studi Roma Tre

e-mail: giulia.bordi@uniroma3.it

\section{Carles Mancho}

Institut de Recerca en Cultures Medievals (IRCVM), Universitat de Barcelona

e-mail: carles.mancho@ub.edu

\section{Valeria Valentini}

Università degli Studi della Tuscia (Viterbo)

e-mail: valeria.valentini@unitus.it

\section{Resum}

Il complesso basilicale di S. Prassede, realizzato da Pasquale I (817-824) all'inizio del suo pontificato, conserva uno dei cicli affrescati più importante della città di Roma altomedievale, e che insieme all'architettura e ai mosaici di questa stessa basilica, concorrono a creare un monumento privilegiato per lo studio della produzione artistica di inizio IX secolo. In questa sede proponiamo un primo approccio allo studio di questi affreschi finora poco indagati e una revisione di quanto detto fino ad oggi su un altro complesso legato alla figura di Pasquale I, S. Cecilia in Trastevere, e più precisamente sulla decorazione del suo battistero. Questa ricerca fa parte di un progetto più ambizioso in cui si punta ad approfondire la Roma di Pasquale I in occasione del $12^{\circ}$ centenario dell'insediamento del pontefice.

Paraules clau: Santa Prassede, Santa Cecilia, Pasquale I, Mosaico, Affreschi, Roma, Pontefice, Martiri

\section{Abstract}

The basilical complex of S. Prassede, commissioned by Paschal I (817-824) at the beginning of his papacy, houses one of the most important frescoe cycles of early medieval Rome, which, together with the architecture and mosaics of this same basilica, turn it into a privileged monument for the study of the artistic production of the early ninth century. This paper proposes a first approach to these so far barely explored frescoes, and a state-of-the-art review of another complex linked to Paschal I, S. Cecilia in Trastevere, and more specifically of the decoration of its baptistery. This research is part of a more ambitious project aimed at deepening our understanding of Rome in times of Paschal I on the occasion of the 1200th anniversary of his elevation as pope.

Paraules clau: Santa Prassede, Santa Cecilia, Paschal I, Mosaic, Affreschi, Rome, Pontiff, Martyrs

\footnotetext{
${ }^{1}$ Benché le riflessioni dalle quali nasce questo articolo siano il frutto condiviso dei tre autori, ognuno di noi è responsabile diretto di una parte. C. Mancho ha affrontato il tema: Gli affreschi di S. Prassede, status quæstionis $e$ problemi da risolvere; $\mathrm{V}$. Valentini ha realizzato la restituzione grafica ricostruttiva del transetto ovest di S. Prassede; G. Bordi è autrice di: Pasquale I e il battistero di S. Cecilia in Trastevere.
} 
Senza alcun dubbio il complesso decorativo più completo del IX secolo conservatosi a Roma è quello di Santa Prassede. La basilica di Pasquale I (817-824), stando alle notizie del Liber Pontificalis, fu realizzata ex novo fra l'817 e l'819 in sostituzione di un vecchio titulus del quale, nonostante gli sforzi, non si è trovata traccia. ${ }^{2}$ Lasciando da parte gli elementi mobili e concentrando il nostro sguardo sui rivestimenti murali, l'edificio conserva ancora in vista i mosaici dell'abside, dell'arco absidale, dell'arco trionfale e dell'intradosso della finestra nord della facciata, nonché l'intera cappella di S. Zenone, ${ }^{3}$ così come una parte significativa - una quinta parte all'incircadegli affreschi del transetto ovest, una parte della decorazione della navata laterale ovest, e una parte dei pavimenti, reimpiegati nella zona presbiterale (FINOCCHIO 2010). ${ }^{4}$

Possiamo affermare quindi che S. Prassede sia una sorta di cartina tornasole della realtà pittorica romana intorno all'inizio del IX secolo. Nessun altro complesso, infatti, ci fornisce punti fermi così solidi per comprendere la latitudine di una committenza artistica pontificia. Non solo conserviamo una parte significativa degli interventi decorativi, soprattutto in mosaico, ma conosciamo anche la cronologia e il promotore dei lavori.

Ma a cosa possono servire questi dati - perché di dati si tratta- in una concezione ottocentesca della storia dell'arte? A niente, e quindi l'insieme è stato trascurato e gli affreschi, importantissimi, sono rimasti praticamente inesplorati fino al giorno di oggi. L'attenzione degli storici dell'arte si è concentrata sui mosaici, il capolavoro artistico, l'opera d'arte in grado di resistere al paragone con altre opere d'arte. ${ }^{5}$ Gli affreschi di S. Prassede, considerati alla stregua di un'evidenza archeologica, di una rovina bidimensionale, quale interesse possono avere nel delineare il Gusto di

\footnotetext{
${ }^{2}$ I significativi sforzi si devono soprattutto a B. M. Apollonj-Ghetti (1961) e A. Muñoz (1918). La problematica riguardo alla posizione dell'antico titulus è dovuta al presupposto che si trattasse o di una basilica (ipotesi dovuta alla notizia di un restauro sotto Adriano I) o di una struttura sotterranea, rispetto alla basilica pasqualina, in un rapporto simile fra il titulus equitii e la chiesa dei Santi Martino e Silvestro ai Monti, a circa duecento metri in linea d'aria da S. Prassede. Come abbiamo suggerito altrove (si veda MANCHo 2016) sia la topografia dell'Esquilino nel punto dove troviamo S. Prassede, che le evidenze archeologiche trovate da Apollonj-Ghetti e da Muñoz, ci portano a pensare a un titulus all'interno di una insula, probabilmente non al pianterreno, in una situazione simile a quella della cappella ancor oggi visibile all'insula sotto Santa Maria in Aracoeli. Logicamente una simile struttura sarebbe stata demolita nel costruire la basilica attuale. Di quel titulus, quindi, oggi non rimarrebbe niente altro che il toponimo della via che ivi portava nell'odierna via di S. Prassede.

${ }^{3}$ La bibliografia sia sui mosaici del presbiterio sia sulla cappella di S. Zenone e piuttosto abbondante; non essendo il soggetto di questo articolo, quindi, rimandiamo alla scheda di S. Pennesi (2006). Riguardo all'orientamento dell'edificio, S. Prassede ha l'abside verso nord, e di conseguenza il braccio del transetto di cui si tratta in questa sede è nel lato ovest.

${ }^{4}$ Non è chiaro, invece, che cosa si possa nascondere sotto le diverse decorazioni posteriori, in particolare nel transetto e nella navata centrale.

${ }^{5}$ E forse è significativo che il primo riferimento ai mosaici si trovi già nelle Vite di G. Vasari (1986 [1550]: 132): «Lauorarono ancora le chiese nuoue di Roma di musaico alla Greca, com'a Santa Prassedia la Tribuna...». Oppure l'attenzione di autori come F. Gregorovius 1973 [1903]: I, 543-545 che, tra l'altro, accenna già alcuni dei nodi dell'analisi di questi mosaici, a cominciare del modello dei Ss. Cosma e Damiano (nonostante l'edizione definitiva sia per il primo volume del 1903 in questo passaggio non ci sono modifiche significative rispetto alla prima stesura pubblicata nel 1870: 55-57).
} 
un'epoca? Questo modo di procedere, purtroppo, non ha investito solo S. Prassede. Ma il suo caso ci consente di porre all'attenzione quanto sia sbagliato questo approccio, poiché quello che mosaico e pittura ci dicono insieme è, sicuramente, molto di più di quello che ci possono rivelare separatamente.

I nostri obiettivi in questa sede, saranno due. Da un lato, accennare agli aspetti che ci permettono di approfondire la conoscenza della parte meno esplorata di questo complesso di dati, cioè, gli affreschi. Dall'altro usare effettivamente S. Prassede come case study intorno al quale provare a delineare un profilo della pittura romana tra fine VIII e prima metà del IX secolo, partendo dal riesame dei dipinti murali conservati nel battistero di S. Cecilia in Trastevere.

\section{Gli affreschi di S. Prassede, status quaestionis e problemi da risolvere}

Fino a dove siamo riusciti a risalire, il primo riferimento agli affreschi del transetto di S. Prassede è di Cancellieri (1806: 136):

In questo Campanile, sopra i Muri dell'Interno, vi sono al secondo Piano, alcune Pitture antichissime, rappresentanti i Fatti dell'Istoria di S. Agnese. È una disgrazia, ch'esse trovinsi in gran parte scancellate: nulladimeno vi sono ancora molte Figure intiere, e nel fine delle Cornici vi sono varie Lettere, che spigano alcuni fatti della sua vita.

L'autore, che studia in realtà il campanile, prende spunto dalla notizia raccolta nel Liber Pontificalis $^{6}$ e identifica lo spazio come oratorio di S. Agnese; di conseguenza associa a questa martire le scancellate scene degli affreschi, nonostante le "varie Lettere, che spigano alcuni fatti" non facciano alcun riferimento a sant'Agnese.

Una cinquantina di anni più tardi l'esistenza di questo spazio e dei suoi affreschi si palesa alla Commissione di Archeologia Sacra. Nei verbali della 5 a sessione del 1858 leggiamo,

Quindi monsignor [Domenico] Bartolini avvertiva, che con sommo piacere avea alla fine trovato nel Campanile della Chiesa di Santa Prassede l'Oratorio di San Pasquale in onore di Santa Agnese Vergine e Martire e che ivi avea vedute delle pitture: ma siccome affermava che le medessime erano per gli anni e per la sozzura oscurate e in un luogo piuttosto elevato non avea potuto bene considerarle. Dimandava perciò che la commissione fattovi erigere un piccolo ponte rispedisse il suo pittore Silvestro Bossi con l'ingiunzione di nettarle, e quindi pregava che la sezione-Chiese vi accedesse per esaminarle. Il segretario fu incom(...) dell'esecuzione della dimanda fatta da monsignor [Domenico] Bartolini.

\footnotetext{
6 "Hic benignissimus præsul fecit in iamdicto monasterium oratorium beatæ Agnetis Christi martyris, mire pulcritudinis exornatum.”, LP. II: 55, benché lui citi il testo princeps (ANASTASIUS 1602: 220).

${ }^{7}$ Pontificia Commissione di Archeologia Sacra, Archivio Storico Documenti, Verbali delle Sedute, C. di A.S. Processi Verbali vol. I ${ }^{\circ}$, Anno $7^{\circ}$, p. 304, Reg. ASD/9 (d'ora in poi citeremo PCAS e il volume)
} 
Che siano passati più di cinquant'anni dalla prima scoperta non stupisce visto in generale lo scarso interesse che suscitava all'epoca la pittura murale di questo periodo. ${ }^{8}$ La notizia resta comunque importante poiché sancisce il momento in cui questi affreschi entrano nel circuito ufficiale e testimonia, se non il primo progetto di restauro, una prima preoccupazione per il loro stato di conservazione.

È di pochi anni dopo la prima analisi sia della struttura che degli affreschi proposta da Alexander Nesbitt (1866: 185-186, pl. XII, 3 p. 198). Innanzitutto, l'autore riconosce nel campanile una parte del transetto. L'attenzione nei confronti della decorazione, sia a livello iconografico che formale, lo porta a un primo tentativo d'identificazione delle scene, seppure ben distante dalla realtà. Basti ricordare che fra le scene identifica, ad esempio, le Nozze di Cana, concludendo che «the subjects seem to be either biblical or legendary». È tuttavia degno di nota il fatto che Nesbitt non abbia ceduto alla tentazione di collegarle all'oratorio di S. Agnese, il che testimonia una riflessione critica sul monumento. Attraverso l'analisi stilistica degli affreschi arriva poi ad affermarne la contemporaneità con 1'edificio, datandoli all'817; e, più importante ancora, collega la realizzazione degli affreschi a quella dei mosaici:

The soffits of the windows show traces of garlands of fruit and flowers, much resembling those in mosaic in the soffits of the triumphal arch and of the apse of this church. These paintings would seem to belong to the period of the building of the church a. d. 817; the style is stiff and dry, and very closely resembles that of the mosaics in the same church.

Queste conclusioni non sono affatto banali. Nelle notizie precedenti i mosaici non vengono mai citati e se c'è un collegamento con Pasquale I è dovuto all'erronea identificazione con l'oratorio di S. Agnese. Nesbitt, invece, parte istintivamente dal confronto con i mosaici e quindi riconosce nella struttura il transetto mascherato della chiesa di Pasquale I, conclusione tutt'altro che evidente all'epoca.

Poco dopo, Leone Nardoni (1870: 6-7), all'oscuro dei precedenti scritti di Cancellieri e Nesbitt, presenta la sua scoperta dell'Oratorio di S. Agnese - a questo punto la terza- con grande enfasi. ${ }^{9} \mathrm{La}$ notizia degli affreschi con $\mathrm{i}$ «fatti dell'istoria di Santa Agnese» non meriterebbe allora attenzione alcuna. se non fosse che nel testo c'è qualcosa di estremamente interessante che ne giustifica la menzione. In concreto si tratta di un'affermazione dell'autore che è passata sotto silenzio: «Al

\footnotetext{
${ }^{8}$ Per quanto riguarda il restauro di questa decorazione conosciamo, per ora, questa notizia e l'intervento della fine degli anni ' 60 diretto da L. Mortari (1969). Nel resoconto di questo ultimo intervento resta chiara l'esistenza di un altro intervento novecentesco.

${ }^{9}$ Risulta quasi comica in questo senso la notizia della sua "scoperta" che egli fa arrivare alla PCAS. "In terzo luogo lesse una lettera del 9 Dicembre 1868 accompagnata da un foglio intorno ad un antico oratorio di S. Agnese in Monasterio del Sig. Leone Nardoni, il quale pregava il Segretario di comunicare tale scoperta, o monumento esistente nella Chiesa di S. Prassede alla Commissione perché ne prendesse cura ed instava ed interesse. S'inserisce negli atti." (Sessione 2a, tenuta giovedì 5 Marzo 1869 all'ora 10 1/2 a. m.). PCAS, vol. II ${ }^{\circ}$, Anno 18 , p. 37, Reg. $\mathrm{ASD} / 10$.
} 
di sopra degli afreschi si veggono alcuni residui di figure in musaico, e delle finestre con entro ancora qualche avanzo degli speculari.». Bisogna riconoscere che l'autore più attento fino a questo momento, A. Nesbitt, non dice nulla a riguardo; ma al contempo va anche evidenziato che il testo di L. Nardoni è più conciso. Tuttavia sembra difficile confondere affreschi e mosaici, e l'autore parla chiaramente di «figure in musaico» sopra agli affreschi. Del resto, individua le finestre e «qualche avanzo degli speculari» il che è tuttora a vista e dimostra un'identificazione accurata. Purtroppo interventi posteriori hanno abbassato il livello del soffitto fino a portarlo al limite superiore delle finestre; ciò non permette oggi di verificare se al di sopra degli affreschi ci potesse essere una qualche decorazione musiva.

Il progresso maggiore nella conoscenza di queste pitture arriva con il testo di M. Armellini (1887: 558-560), il primo a fare una analisi diretta e approfondita di esse. L'autore si basa fondamentalmente sulla lettura delle iscrizioni e non delle immagini. Questo si evince dal fatto che collega i testi ai riquadri soprastanti come se fossero didascalie,

...disposti a tre ordini, gli uni sopra gli altri, e sotto ciascun quadro corre una fascia rossa, ove con lettere bianche sono scritte le cose dichiarative dei soggetti in essi espressi. ${ }^{10}$

In realtà si tratta di un errore perché i testi riguardano le immagini sottostanti. Malgrado ciò ad Armellini va il merito di aver trascritto per la prima volta le iscrizioni garantendone, così, la memoria.

Paradossalmente, Josef Wilpert, le cui tavole acquerellate degli affreschi di S. Prassede restano uno dei capisaldi per la loro conoscenza, ci ha lasciato scritto molto poco a riguardo. L'autore ha dedicato loro un articolo pubblicato nel 1908 (:179-180) nel quale si limita tuttavia a fare una serie di precisazioni e correzioni alla lettura delle iscrizioni proposta da M. Armellini. Successivamente, nella Die römische Mosaiken und Malereien, dove appaiono le già citate tavole, Wilpert cita gli affreschi solo nel confronto stilistico con quelli dei Santi Quirico e Giulitta in Santa Maria Antiqua (WILPERT 1916: II, 651). Stando al testo, quindi, si è indotti a pensare che, nell'economia della sua monumentale impresa, Wilpert abbia dedicato poca attenzione alle pitture di S. Prassede $o$ per mancanza di interesse $o$, più probabilmente, per non aver avuto il tempo necessario di approfondirne la conoscenza. Le bellissime tre tavole, i cui originali sono oggi conservati presso il Pontificio Istituto di Archeologica Cristiana (Ibid.: IV, 202-204), sono il frutto di un processo estremamente articolato e costoso di realizzazione e testimoniano quanto Wilpert considerasse importante documentare questi affreschi (fig. 7-9). ${ }^{11}$ Non c'è dubbio che oggi se siamo debitori ad Armellini per la memoria delle iscrizioni di corredo agli affreschi, dobbiamo, invece, a Wilpert l’immagine più nitida giunta sino a noi di questi ultimi, realizzata tra il 1905 e il 1910.

\footnotetext{
${ }^{10}$ L'opera, di un grande successo, ebbe almeno tre edizioni. Per quanto riguarda agli affreschi di S. Prassede, le successive (1891 e 1942) non aggiunsero nulla a quello già detto nella prima. L'evidenziato in grassetto è nostro.

${ }^{11}$ Non ci soffermeremo in questa sede sull'affascinante processo di creazione delle fotografie acquerellate di Josef Wilpert, per il quale si rimanda ai recenti studi di G. Bordi (2009a; BorDi 2009b: 458).
} 
Incredibilmente, da questo momento in poi, cioè da quando gli affreschi potevano essere più largamente conosciuti e, soprattutto, più approfonditamente studiati, cade come un macigno il silenzio che li avvolgerà fino agli anni '90. Ovviamente sono diversi gli autori che segnalano la loro esistenza. Pietro Toesca, padre della storia dell'arte italiana, dopo aver dedicato circa sette pagine ai mosaici di Pasquale I, si riferisce ai nostri affreschi identificandoli come "i dipinti presso la sagrestia di S. Prassede", e li liquida con il commento: "non sono che umili opere, non del tutto in sé omogenee né di data sicura" (ToEsCA 1907: 402-3). Giudizio tranchant che rivolge a gran parte della pittura romana del IX e X secolo, citata nello stesso paragrafo.

Stupisce che le solide basi gettate dai lavori di A. Nesbitt, M. Armellini e J. Wilpert non abbiano stimolato, già al tempo della loro comparsa, l'interesse ad approfondire lo studio di queste pitture. L'imponente lavoro di G. Matthiæ (1987 [1965]: 173-195) ci dà la conferma che ancora negli anni Sessanta del secolo scorso esse erano considerate poco più che "comparse" sulla scena dell'arte altomedievale romana:

Alla pittura murale, sempre legata a committenti o ad intenti più modesti, la produzione musiva non solo sottrasse le ordinazioni più importanti ma, avendola relegata in un rango minore, le tolse anche la possibilità di un rapido adeguamento alle nuove conquiste e a quel rigorismo stilistico che era il riflesso immediato dei grandi avvenimenti del tempo. La pittura in affresco, almeno stando alle opere che ci sono conservate, trascinò una esistenza stentata e risentì con notevole ritardo dei modi invalsi in quella musiva. (Ibid.: 173)

È sempre difficile, se non impossibile, sottrarsi alle tendenze storiografiche che segnano il nostro percorso di storici; e inoltre non si può non ammettere che nella Storia dell'arte frequentemente è saltato il necessario equilibrio fra storia e arte, a detrimento di opere come gli affreschi di S. Prassede, ritenute di "rango minore". È impensabile, infatti, immaginare che uno storico possa rinunciare a studiare un documento perché è scritto con un inchiostro di bassa qualità o presenta una sintassi difettosa. E qui vediamo come il peso di un certo concetto di arte ha fatto sì che Matthiæ si sia dimenticato della storia. In questo paradigma l'analisi di Matthiae degli affreschi di S. Prassede resta confinata ad un puro confronto qualitativo con i mosaici della stessa basilica, bollando gli affreschi come un prodotto di livello nettamente inferiore eseguito da "pittori dotati di minori possibilità". Il loro valore intrinseco viene totalmente negato e accanto ai mosaici, possono essere soltanto spiegati per una qualche tipo d'incapacità, sia essa esecutiva, di committenza, o economica. In questo schema non c'è spazio per altre interpretazioni legate alla scelta, alla funzione o all'adeguamento ad esigenze dettate dagli spazi. Di conseguenza,

...mentre i musivari ebbero il compito di dare al fatto [la traslazione delle reliquie da parte di Pasquale I] un aspetto di teofania, ai frescanti spettò quello più umile degli episodi storici relativi ai martirii di quei beati e con notevole monotonia essi ripeterono, con scarse varianti i momenti del santo dinanzi al giudice e del suo supplizio. È una narrazione che vuol essere storica ed edificante e riesce soltanto triste e noiosa, quasi l'anticipazione medioevale dell'antologia terrificante che la Controriforma collocherà nel perimetro di S. Stefano rotondo. (Ibid.: 174) 
La genialità di G. Matthiæ, però, risiede nel fatto di aver colto, nonostante rimanga imbrigliato nelle questioni stilistiche, la specificità del ciclo di S. Prassede, anche se la connoti in modo negativo. Effettivamente, l'insieme di affreschi del transetto di S. Prassede è ripetitivo quindi noioso - ed ha uno scopo simile, probabilmente, a quei programmi controriformisti che cercarono nel primo cristianesimo, e più precisamente nell'iconografia "paleocristiana", le basi del cattolicesimo uscito dal Concilio di Trento. ${ }^{12}$

Nell'importante studio di C. Bertelli (1983), Roma rimane intrappolata dentro ad una tempesta perfetta, nella quale la città assume il ruolo di spettatrice sulla scena che vede due grandi protagoniste: la renovatio carolingia e l'arte bizantina. È interessante l'inserimento da parte dell'autore in questo dialogo a due di Ravenna, che sposta l'attenzione verso un contesto sempre bizantino, ma nettamente italico e di lunga data. La ricerca di botteghe di mosaicisti in quel contesto e la notizia del restauro compiuto da Leone III a Sant'Apollinare in Classe (Ibid.: 79) avrebbero potuto permettere all'autore di sottrarsi a quel binomio. Invece, l'analisi della situazione romana del IX secolo resta ancorata fra la "Roma carolingia" e gli apporti bizantini. Così, da un punto di vista formale, dice C. Bertelli, "Orientali sono anche i mosaici, i quali non hanno però riscontro in quanto di direttamente bizantino conosciamo prima e subito dopo il silenzio iconoclasta." (Ibid.: 81), e da quello iconografico 1"'intelaiatura" è romana.

È interessante, per sottrarsi alla seduzione del mosaico, dove l'oro e lo smalto trasmettono un sensuoso fascino di ricchezze perdute, confrontare i mosaici con gli affreschi nel transetto, di Santa Prassede, dovuti agli stessi maestri e che un tempo dovevano essere visti simultaneamente. Negli affreschi cogliamo meglio la brutalità d'un discorso semplificato all'estremo, tutto immedesimato nell'azione e dove il linguaggio tardo antico è completamente bruciato ed ha lasciato soltanto tracce mnemoniche, appoggi alla comprensione figurativa. (Ibid.)

In realtà, anche se il discorso è più articolato, non siamo lontani da dove eravamo rimasti con G. Matthiæ.

È stato solo alla fine degli anni Novanta che l'interesse per Santa Prassede si è riattivato sia per quanto riguarda l'architettura, con il libro di M. Caperna (1999), sia per quanto riguarda gli affreschi. Nel caso di questi ultimi, bisogna considerare, fondamentalmente, la tesi di laurea di S. Pennesi (1998). Purtroppo la ricercatrice non ha avuto occasione di pubblicare gli esiti di questo studio che riteniamo essere uno dei lavori più esaurienti sull'argomento realizzati fino ad oggi. Quindi, anche se non è frequente dover rimandare a una tesi di laurea, in realtà siamo di fronte all'unico studio monografico dedicato a questo insieme pittorico. Pennesi risolve principalmente il rapporto fra iscrizioni e la decorazione, e di conseguenza l'identificazione dei soggetti rappresentati. Da questo punto di vista è un lavoro impeccabile. L'autrice si pone il

\footnotetext{
${ }^{12}$ Non è un caso che Santa Prassede, nonostante le trasformazioni subite si sia conservata; e non lo è, affatto, che il
} cardinale titolare responsabile di questa conservazione-nonostante-la-trasformazione sia stato san Carlo Borromeo. 
problema del rapporto tra mosaici e affreschi e del loro inserimento nel contesto pittorico della Roma del tempo, sia a livello formale sia iconografico. ${ }^{13}$

Tuttavia, la ricerca di Pennesi presenta oggi, logicamente, dei limiti; due, in sostanza. Il primo è il fatto di essere stata sviluppata in parallelo all'elaborazione del testo di M. Caperna (1999) sull'architettura che, quindi, la studiosa non prende in considerazione e che la porta ancora a basarsi esclusivamente sul lavoro di R. Krautheimer e S. Corbett (1971). Il secondo è di tipo concettuale: le "fondamenta" dell'analisi di Pennesi sono in parte superate. L'autrice per inquadrare l'intervento pasqualiano adotta il Profilo della Roma del secolo IX di R. Krautheimer (1981). Questo testo pur essendo ancora basilare presenta ormai, come abbiamo avuto occasione di sottolineare altrove (MANCHO 2011), una serie di incrinature nel discorso, specie per quanto riguarda la questione di "Roma carolingia".

Lo status quaestionis appena delineato, ci consente di farci un'idea di cosa è acquisito sulle pitture di S. Prassede e di cosa invece rimane ancora da indagare oggi, all'inizio del $2017 .{ }^{14}$ Innanzitutto appare chiaro che lo studio di questi affreschi è un problema complesso da affrontare secondo due livelli di indagine. Il primo deve mettere al centro il monumento del quale gli affreschi sono il decor. Nessuno studio ha ancora mai affrontato la decorazione di S. Prassede considerandola parte di un unico grande progetto. Ed è necessario sottolineare che siamo di fronte all'unico complesso pascaliano conservatosi che permetta un tale esercizio. Siamo oramai lontani dal tempo in cui l'architettura, da sola e a determinate condizioni, bastava a spiegare o a giustificare la "renovatio carolingia", i mosaici, il contrasto bizantino nella plastica, nonché ad ignorare la pittura perché non perfettamente accordata con i mosaici; ecc. Il progetto di S. Prassede era uno e aveva a capo il pontefice, allo stesso modo in cui, mutatis mutandis, il MAXXI di Roma, nella sua totalità, è un progetto di Zaha-Hadid e a nessuno verrebbe mai in mente di parlare di "bottega romana" riferendosi ai muratori che hanno steso i pavimenti in resina del museo.

Proprio per questo, il secondo livello mette al centro la città. L'ideazione di una basilica come S. Prassede, con tutte le caratteristiche che la contraddistinguono, era possibile soltanto a Roma alla fine del secondo decennio del IX secolo. Non prima e non dopo. Non c'è dubbio che nel concepire S. Prassede, Pasquale I avesse in mente la città, la Roma che poteva servire o meno ai suoi progetti (MANCHO 2016). Questa lettura tuttavia, troppo generica, non ci soddisfa più. La

\footnotetext{
${ }^{13}$ Un articolo comparso l'anno successivo (ZACCAGNINI 1999) non ha alcun interesse se non quello di fungere da contrasto alle correzioni fatte da J. Wilpert (1908) alla proposta di M. Armellini: l'autrice non conosce il testo di Wilpert e quindi fa, rispetto alla proposta di Armellini la stessa analisi dell'erudito tedesco ma a novanta anni di distanza.

${ }^{14}$ Paradossalmente, lavori più o meno recenti che si occupano della decorazione di S. Prassede o non apportano nulla (Goodson 2010: 235-241 che si basa in ZACCAGNINI 1999) o continuano a smembrare l'opera per concentrarsi in un unico tassello del puzzle (THunø 2014).
} 
domanda, a cui dobbiamo trovare delle risposte precise, interessa anche la decorazione murale dell'edificio. ${ }^{15}$

Essa si conserva parzialmente, in una parte dell'antico transetto ovest dell'edificio, trasformato in campanile nella seconda metà del XIII secolo (fig. 1-2) ${ }^{16}$ La trasformazione comportò la costruzione di un muro verticale che ancora oggi separa il transetto dal presbiterio. La zona di passaggio fra la navata laterale e il transetto, segnata da una colonna con un bel architrave, fu murata. In questo modo si costituì la torre all'interno delle strutture preesistenti con l'aggiunta di un piano al di sopra della quota massima del transetto, tuttora esistente, per la collocazione delle campane. Oggi questo "campanile" presenta un primo livello in cui i muri sono stati completamente picchettati e dove, quindi, non si conserva traccia alcuna di malta di rivestimento. Tramite una scala a chiocciola in ferro battuto posta nell'angolo nord-ovest del transetto si accede ad un primo piano, dove gli affreschi conservati convivono con l'organo (fig. 3). Questo piano è situato al livello del coretto laterale e al disopra delle finestre già del transetto, un soffitto segna il secondo piano, accessibile soltanto dall'esterno (fig. 11).

La traccia aperta nei muri nord e sud del transetto per appoggiarci il muro di chiusura est, interrompe oggi lo sviluppo degli affreschi verso il presbiterio. Non è da escludere, però, che sotto alla decorazione moderna di finte crustce marmoree, che chiude la decorazione a mosaico dell'arco absidale, ci siano ancora gli affreschi che, supponiamo, arrivassero fino al livello di questa decorazione. ${ }^{17}$

L'analisi degli affreschi, uno dei "tasselli" della decorazione di S. Prassede, è fondamentale per capire il complesso, e per farlo bisogna partire dalla realtà "materiale" di quel che conserviamo: un sesto all'incirca della decorazione del braccio ovest del transetto. Già nella fotografia acquarellata pubblicata da Wilpert nel 1916 (fig. 7-9) si evince la conservazione parziale di soli cinque registri del totale che rivestiva questo transetto ovest.

La caduta dell'intonaco a sinistra della prima scena del primo registro ci fornisce un'informazione preziosa perché ha messo in luce la piattabanda di scarico sopra all'architrave poggiante sulla colonna che segna il passaggio fra la navata laterale ovest e il transetto. Questo importante dettaglio ci permette di affermare che non c'erano altre scene prima di questa e che quindi la narrazione cominciava qui.

${ }^{15}$ E non c'è dubbio che il libro di Goodson (2010) no risponde alla questione anche se fornisce un'importante quantità di materiali che semplificano la ricerca in questo vettore.

${ }^{16}$ Dai calcoli fatti da V. Valentini nella restituzione ipotetica la superficie totale suscettibile di essere stata dipinta nel progetto di Pasquale I era di 303m2 dei quali conserviamo oggi 52,73m2 di affreschi, un $17,4 \%$ del totale del transetto ovest.

${ }^{17}$ Sempre a livello fisico, nell'ultima nostra visita a Santa Prassede, in occasione del seminario "Grata più delle Stelle", Roma-La Sapienza e Roma Tre, abbiamo avuto occasione di comprovare i problemi di conservazione degli affreschi fra il secondo ed il terzo registro dell'angolo sudovest. I primi esami visuali hanno consigliato di proporre un intervento conservativo che speriamo si possa realizzare a breve. 
Le scene oggi conservate sono ventuno quasi tutte identificate (PENNESI 1998: 74-103) (fig. 10).

Nel registro numero 1 non vi è dubbio che, nonostante la caduta di parte della superficie pittorica, siamo di fronte a un ciclo dedicato alle sante Prassede e Pudenziana. (fig. 10 1, a). Nel registro numero 2, le scene conservate sono dieci in tutto e gli episodi narrati sono dedicati ai santi Basilissa (fig. 10 2, a), Giuliano e Celso (fig. 10 2, b), Marcionilla, Antonio (fig. 10 2, c) ed il neofita Anastasio, martiri di Antinopoli sotto le persecuzioni di Diocleziano e Massimano. Nel registro numero 3, le scene giunte a noi sarebbero di nuovo dieci e i martiri rappresentati Claudio e i figli Giasone e Mauro più settanta soldati (fig. 10 3, a; 4-5), Crisanto e Daria (fig. 10 3, b; 6) sotto le persecuzioni di Numeriano (283-4). Il riconoscimento delle scene fin qui elencate è il frutto del riscontro tra iscrizioni pictae e lettura iconografica delle pitture, ma va ricordato che la superficie dipinta visibile in situ e le tavole di Wilpert attestano la presenza di un numero superiore di scene.

Nel primo registro 1 si conservano brani di almeno altri quattro scene, in nessuna dei quali resta però traccia di iscrizioni (fig. 10 1, a, 3, 7-9), ma applicando lo schema dei registri 2 e 3 si potrebbe arrivare, almeno a nove. Nel registro 4, finora non analizzato, mettendo insieme i dati delle fotografie di Wilpert, dei frammenti conservati e dello spazio disponibile fra le quattro finestre, potremmo contare, almeno, altre sette scene e lo stesso schema funzionerebbe anche per il quinto registro, dove forse si riconoscono frammenti di un'iscrizione (fig. 13). Quindi, nella zona oggi visibile, il totale delle scene arriverebbe a circa quarantatré. Quasi la metà di queste è identificabile tramite le iscrizioni conservate. Ipotizzando un simile sviluppo nel transetto orientale il totale arriverebbe a ottantasei scene senza considerare il fatto che non conosciamo il numero di quelle presenti fra la zona conservata e il mosaico absidale.

L'analisi dei dati disponibili ci permette di spingerci ancora oltre. Nella ricostruzione a cui abbiamo lavorato con Valeria Valentini possiamo vedere, nella parte superiore, che la quota massima all'interno del transetto consente di supporre l'esistenza di un sesto registro della stessa altezza degli altri e, quindi, atto a contenere altre scene martiriali -almeno dieci, se manteniamo lo schema precedente-. Resta uno spazio di circa un metro, a chiusura del muro, dove possiamo ipotizzare la presenza di una fascia decorativa.${ }^{18}$ Rimane il problema, nella parte inferiore, di come potessero essere decorati i quasi cinque metri esistenti fra la base del primo registro narrativo e il pavimento della basilica. Si potrebbe supporre la presenza di un velario; tuttavia, non si conoscono casi di velari alti circa cinque metri. Sono invece diversi i complessi altomedievali romani dove il registro scandito da racconti agiografici è chiuso, nella parte inferiore, da una teoria di santi sotto

${ }^{18}$ Evidentemente, un'altra possibilità è che la fascia decorativa si estendesse dalla finestra fino alla sommità del muro. 
alla quale si sviluppa poi un velario. ${ }^{19}$ Lo spazio disponibile, quindi, permetterebbe di immaginare un settimo registro pronto ad accogliere una teoria di santi, sotto al quale ci sarebbe uno spazio di 2,40 metri di altezza dove sviluppare un velario; come mostreremo più avanti, forse non è casuale che queste siano anche le dimensioni del velario nel battistero di S. Cecilia.

L'argomento per supporre un tale schema della decorazione del transetto è che il primo registro con scene martiriali è occupato dall'inizio della storia di Prassede e Pudenziana (fig. 10 1, a). Essendo la basilica dedicata a Prassede sembrerebbe strano che sotto alla storia di questa martire ci fosse un registro dedicato ad altri martiri. La posizione diventerebbe preferenziale, relegando la titolare ad una posizione secondaria. È questo il motivo per cui rifiutavamo l'idea di altri registri sotto a quello. Evidentemente, però, una teoria di martiri servirebbe non solo a presentare molti più santi rispetto a quelli presenti nelle scene, ma sarebbe anche un ottimo e logico collegamento con i martiri trionfanti dell' arco, appunto, trionfale.$^{20}$ In questa ipotesi le scene salirebbero a circa 106 per tutto il transetto oltre alle figure ieratiche della teoria di martiri.

In sintesi, quindi, nel transetto di S. Prassede la decorazione pittorica era organizzata, probabilmente, a partire da un primo livello occupato da un velario, un secondo livello con una teoria di martiri e sei registri sovrapposti con scene di martiri. Una fascia decorativa nella parte superiore sarebbe servita a unificare le decorazioni, quella musiva e quella pittorica, fungendo anche da collegamento fra un lato e l'altro del transetto (fig. 12).

Al di là dell'ipotesi ricostruttiva, la logica storiografica con cui ci si è avvicinati alla basilica di Santa Prassede ha fatto sì che, nell'identificazione dei cicli martiriali, punto di riferimento imprescindibile sia stata sempre la celebre iscrizione con l'elenco dei martiri traslati dalle catacombe (fig. 14). In realtà in essa vi sono citati soltanto Mauro, Giasone, Crisanto, Daria, Prassede e Pudenziana, quindi, soltanto sei dei tredici che subiscono il martirio nelle scene identificate. La percentuale è piuttosto bassa, e anche se riuscissimo a identificare tutte le scene e i rispettivi martiri, ci sarebbe comunque un gruppo importante di martiri non ricordato nell'iscrizione ma presente negli affreschi. Come spiegare questa asimmetria?

Da una parte, bisogna riconoscere che l'iscrizione non raccoglie l'insieme dei 2300 corpi di martiri che si suppone siano stati traslati dalle catacombe, dall'altra che neanche gli affreschi potevano riprodurre un tale insieme di corpi, nonostante lo sviluppo che abbiamo ipotizzato.

\footnotetext{
${ }^{19}$ Questo tipo tripartito di scansione della parete dipinta è attesta a Roma, ad esempio, a S. Maria Antiqua, nella navata sinistra, nelle pitture del tempo di Paolo I, a S. Adriano al foro romano, nei dipinti oggi staccati e conservati al Museo Nazionale Crypta Balbi degli anni di Adriano I e sulla parete sinistra della chiesa di S. Passera alla Magliana (BORDI 2008: 147-152). Quest'ultimo esempio, è interessante quest'ultimo esempio in particolare dato che la decorazione, con scene di s. Prassede, è stata attribuita a Pasquale I (Falla 2011).

${ }^{20}$ Ricordiamo che è questa la prima volta che l'arco maggiore di ingresso nel transetto dalla navata centrale viene così chiamato (LP. II: 54): "Simili modo et arcum triumphalem eisdem metallis mirum in modum perficiens compsit."
} 
Dunque i cicli del transetto probabilmente rispondono a una logica interna che andrebbe chiarita. In realtà è già notevole il fatto che tutte le scene conservate appartengano soltanto a cinque racconti agiografici, cioè ai cicli dei santi: Prassede, Basilissa, Giuliano e Celso, Claudio e Ilaria, Crisanto e Daria. La domanda sarebbe: perché questa selezione?

Bisognerebbe anche indagare se la scelta dei martiri rappresentati sia in connessione con il complesso musivo dell'abside e, soprattutto, dell'arco trionfale oppure se si tratti di una scelta, come suppone Pennesi, collegata all'uso del transetto e della sua decorazione. Probabilmente aggiungerebbe dati alla nostra conoscenza di questo complesso decorativo capire quali scene erano viste, a seconda della posizione dei fedeli o dei pellegrini, nel transetto e nelle navate laterali. Dato lo schema generale ripetitivo di una parte sostanziale delle scene conservate, alcune deformazioni morfologiche delle figure suggeriscono che in tutto o in parte fossero previsti dei punti di vista privilegiati dai quali fruire le immagini; per esempio entrando ed uscendo dalla cripta anulare. Una migliore conoscenza dell'assetto presbiterale, sul quale hanno cominciato a lavorare A. Ballardini e M. Caperna, di sicuro ci fornirà nuovi dati in questo senso.

Già dalla restituzione del transetto ovest qui proposta si evince che il risultato doveva essere veramente imponente (fig. 12). Immaginiamo cosa fosse per i pellegrini che arrivavano a Roma in cerca delle reliquie dei martiri - 2.300 corpi raccolti da Pasquale I - la visita alla basilica di S. Prassede. Dopo un passaggio nella navata laterale, intravedendo la Gerusalemme Celeste dei mosaici dell'arco trionfale e i martiri con le palme e le tonache bianche, in un atteggiamento di attesa simile alla loro processione, i pellegrini entravano nel transetto dove gli occhi di una sessantina di martiri li fissavano; al di sopra sei livelli di scene ripetitive, difficilmente identificabili ma con un elenco completo delle sevizie inflitte ai martiri, preparavano la discesa nella cripta dove la prossimità ai martiri era probabilmente parossistica - per poi emergere dall'altra parte e ritrovare lo stesso e impressionante quadro. Forse la sensazione di vertigine provata dai fedeli non sarà stata troppo lontana da quella descritta dal patriarca Fozio nell'omelia per la Theotokos di Pharòs (c. 880) a Costantinopoli:

It is as if one had entered heaven itself with no one barring the way from any side, and was illuminated by the beauty in all forms shining all around like so many stars, so is one utterly amazed. Thenceforth it seems that everything is in ecstatic motion, and the church itself is circling round. (MANGO 1971: 185)

Al di là di queste considerazioni restano sempre un soggetto di riflessione interessante, a dimostrazione di quanti livelli di lettura possa racchiudere un tale intervento decorativo, le didascalie pictae che accompagnavano gli affreschi. Un testo ad hoc tanto importante oggi per noi, ma che fu letto soltanto una volta: mentre veniva dipinto. 
Trattandosi del complesso di cicli martiriali più importante della città di Roma nell'altomedioevo bisognerebbe indagare, come già timidamente aveva iniziato Pennesi (1998: 104-114), l'evoluzione di questo tipo di pittura a partire dalla cappella di Teodoto in Santa Maria Antiqua (741-752) fino a Santa Prassede e per tutto il IX secolo. ${ }^{21}$

\section{Pasquale I e il battistero di Santa Cecilia in Trastevere}

Il quadro sulla decorazione pittorica delle chiese di Roma tra l'ultimo quarto dell'VIII secolo e la prima metà del IX secolo è ancora piuttosto fluido.$^{22}$ Lo studio delle pitture del transetto di Santa Prassede, avviato da C. Mancho in anni recenti, si presenta come un'importante occasione per affrontare uno stato dell'arte della pittura a Roma tra VIII e IX secolo e provare a rileggere una serie di contesti decorativi i quali, a causa sia del precario stato di conservazione in cui versano sia della perdita pressoché totale di nessi con una committenza o una cronologia certe, sono rimasti in bilico tra i due secoli, ancorati spesso alla generica datazione fine VIII- primi decenni del IX secolo. Mi riferisco, in base ad un censimento preliminare, alle pitture della parete sud della chiesa di Santa Passera alla Magliana (Manacorda 1994: 37-39; Falla-Castelfranchi 2011) (fig. 16), a quelle dell'oratorio medievale sotto la basilica dei Santi Giovanni e Paolo al Celio (fig. 17), ${ }^{23}$ alla decorazione delle pareti nord e sud dell'oratorio dei Quaranta Martiri al Foro romano (fig. 18), ${ }^{24}$ ad alcuni pannelli di tipo iconico conservati nell'atrio di Santa Maria Antiqua (Osborne 1987: 191-194) (fig. 19), al primo strato delle pitture della cappella "H9" in San Lorenzo fuori le mura (BoRDI 2007: 213-217) (fig. 20). Alle quali propongo, inoltre, di aggiungere "nuove" acquisizioni, prendendo in considerazione alcuni contesti pittorici la cui datazione è opportuno riconsiderare. Il primo contesto da cui partire in apertura del percorso di ricerca avviato in occasione dell'anniversario del pontificato di Pasquale I (817-824), è la decorazione pittorica conservata nel battistero di Santa Cecilia in Trastevere, all'interno di un complesso monumentale dove la committenza pascaliana, come è noto, è acclarata (fig. 21). Tornato alla luce durante la campagna di scavi condotta da Parmegiani e Pronti tra il 1987 e il 1999, il battistero si era insediato, secondo la ricostruzione dei due studiosi, nella prima metà del V secolo all'interno di un complesso preesistente nelle cui strutture è stata riconosciuta una domus del II secolo a.C., assorbita nella prima metà del II secolo d.C. all'interno di un'insula, il cui cortile interno ricalcò il perimetro dell'atrio preesistente (Parmegiani, Pronti 2007a: 1125) (fig. 22). Il battistero andò a occupare la grande aula posta a nord del cortile dell'insula e

\footnotetext{
${ }^{21}$ L'argomento, per il VII e l'VIII secolo è stato analizzato da Jessop 1999. Le più recenti pubblicazioni su complessi come S. Maria in via Lata (Bordi 2015), S. Maria Antiqua (Andaloro, Bordi, Morganti 2016) o le catacombe di Calepodio (MinAsi 2009), fra altri, dovrebbero permetterci un approfondimento maggiore di quel che era possibile un po' di anni addietro.

${ }^{22}$ Il quadro di riferimento per questo periodo è ancora quello delineato da Maria Andaloro nell'aggiornamento al volume di MatThiae 1965: Andaloro 1987: 263-295, spec. 282-286.

${ }^{23}$ Germano di San Stanislao 1894: 417-440; Curzi 1999: 607-616; Ranucci 2015: 313-327.

${ }^{24}$ Romanelli-Nordhagen 1964: 63; Gulowsen 1994: 117; Bordi 2016, p. 286.
} 
doveva essere annesso al titulus Sanctae Caeciliae del quale, tuttavia, non sono state riconosciute evidenze archeologiche (PARmegiani, Pronti 2007b: 41-55). Nel vasto ambiente già nel IV secolo era stata istallata al centro una vasca circolare ed era stata aperta una "trifora" sul lato orientale. Nella stessa fase, in altri due ambienti dell'insula, posti a est dell'aula, era stato costruito un balneum (Parmegiani, Pronti 2007a: 25-33) che, nel secolo successivo, verrà poi considerato il luogo del martirio di santa Cecilia (PARmegiani, Pronti 2007b: 44). Il fonte battesimale sfruttò la vasca del bacino preesistente mantenendo lo stesso diametro interno mentre il perimetro esterno, esagonale, fu ritmato da pareti ad andamento concavo alternate a brevi tratti rettilinei (Ibid.: 45 46). In base alla ricostruzione proposta da Parmegiani e Pronti, l'aula battesimale all'inizio del V secolo doveva presentare il seguente aspetto: al centro era collocata la vasca rivestita all'interno e all'esterno da lastre marmoree e sormontata da un tegurio sorretto da colonnine con capitelli; sulla parete settentrionale si apriva un'ampia finestra, su quella occidentale una porta; la parete meridionale era chiusa, mentre quella orientale comunicava con l'ambiente adiacente attraverso tre arcate rette da due colonne con capitelli; la pavimentazione dell'ambiente era a lastre di marmo (Ibid.: 44-50, fig. 68). Sempre secondo i due archeologi, già nel V secolo, le pareti nord, ovest ed est dell'aula accolsero una decorazione pittorica, oggi conservata solo per una altezza massima di m. 2,30 circa (Ibid.: 47) (fig. 23). Sulla parete settentrionale, dove restano i brani più consistenti, si legge una decorazione articolata in tre registri: il primo è caratterizzato da velari dipinti (alti circa m. 1,40) (fig. 24), il secondo da un'alta fascia dove corre un lungo festone con foglie e boccioli (alto circa $\mathrm{cm} \mathrm{38),} \mathrm{il} \mathrm{terzo} \mathrm{da} \mathrm{riquadri} \mathrm{(larghi} \mathrm{circa} \mathrm{cm} \mathrm{172)} \mathrm{dei} \mathrm{quali} \mathrm{oggi} \mathrm{resta}$ solo la cornice inferiore e l'attacco dei montanti laterali. Questi ultimi dovevano sicuramente ospitare scene a carattere narrativo (fig. 24). ${ }^{25}$

Il velario corre lungo tutta la parete ed è scandito da una decorazione a tre rotae, una di dimensioni più grandi affiancata da due più piccole, intercalata da motivi a "picche" chiusi in alto e in basso da una banda a tre fettucce rossa, gialla e rossa. Questo velario presenta una peculiarità sulla quale vale la pena soffermarsi. Esso non è dipinto con i tipici panneggi, segnati da pieghe in corrispondenza dell'attacco del finto tessuto alla parete tramite occhielli, ma sembra piuttosto concepito come un lungo e pesante drappo srotolato e appeso in modo da restare teso. Usando la terminologia del Liber Pontificalis, potrebbe trattarsi della rappresentazione di un tipo di tendaggio più simile a una cortina ${ }^{26}$ piuttosto che a dei vela.$^{27}$ Secondo Parmegiani e Pronti la singolarità di questo velario, per il quale affermano di non aver trovato alcun confronto, è indice della sua antichità che per i due autori è da riferire al V secolo (PARMEGiani, Pronti 2007b: 47). Vari elementi, tuttavia, inducono a posticipare la datazione di questa decorazione e a proporre una

\footnotetext{
${ }^{25}$ Ringrazio Neda Parmegiani e Alberto Pronti per avermi con grande disponibilità e generosità "aperto le porte" dell'area archeologica del battistero di Santa Cecilia in Trastevere.

${ }^{26}$ La cortina era un tendaggio di seta pesante impiegato nelle basiliche in corrispondenza di ampi spazi come gli ingressi principali o gli archi trionfali: PetriagGi 1984: 44; Osborne 1992: 315-316.

${ }^{27}$ I vela erano tendaggi leggeri di seta appesi usualmente tra le colonne che della navata maggiore o di quelle minori: Petriaggi 1984: 44; Osborne 1992: 315-316.
} 
nuova scansione delle fasi decorative del battistero. Innanzitutto, l'uso di decorare la zoccolatura di un edificio di culto con velari dipinti è attestato a Roma non prima del VI-VII secolo; fino a questa data lo spazio compreso tra il pavimento e i programmi decorativi dispiegati sulle pareti ospita crustae marmoree o imitazioni in pittura delle stesse. ${ }^{28} \mathrm{I}$ casi cronologicamente più alti di velari dipinti a me noti sono quelli conservati sulla parete sud della chiesa inferiore di San Crisogono (VI secolo) ${ }^{29}$ e nell'ultimo tratto della parete della navata est in Santa Maria Antiqua (metà VII secolo). ${ }^{30}$ In secondo luogo i battisteri eretti a Roma tra V e VI secolo sembrano privilegiare una decorazione parietale a crustae marmoree piuttosto che a intonaco dipinto. Si consideri, ad esempio, il vicino battistero di San Crisogono, datato al V secolo, del quale si leggono ancora sulla parete ovest, sotto a intonaci più recenti, chiare tracce della preparazione con tubi fittili dell'originaria decorazione a incrustationes $;{ }^{31}$ oppure quello di San Clemente, datato agli anni Trenta del VI secolo, che conserva, lungo il perimetro dell'aula, la malta di allettamento con l'impronta delle lastre e alcuni frammenti di crustae ancora in opera (GUIDOBALDI 1997: 459491, spec. 483-488). È assai probabile che la decorazione originaria delle pareti del battistero di Santa Cecilia fosse anch'essa a crustae marmoree, successivamente asportate e sostituite con una decorazione a intonaco dipinto. Quest'ultima, quando fu inserita? Il confronto con due velari romani poco noti può, a mio avviso, aiutare a circoscrivere la datazione di questa decorazione. Si tratta dei vela ancora oggi visibili nell'oratorio medievale nel complesso delle case romane sotto la basilica dei Santi Giovanni e Paolo (fig. 25) e nella cosiddetta cappella "H9" in San Lorenzo fuori le mura (fig. 26). Il primo esempio è conservato in ampi brani sulla zoccolatura della parete est dell'oratorio (RAnucci 2015: 318, 320 e figs. 9-13, tav. XVII. a1), si tratta di un velario con caratteristiche analoghe a quello di Santa Cecilia, anche se la decorazione del drappo è più articolata e presenta l'alternanza di motivi a "spade incrociate e orbicoli", a rotce e a "picche". Questo velario, attribuito in passato alla seconda metà dell'VIII secolo (OsBORNE 1992: 341), o considerato parte della decorazione aggiunta nel XII secolo su questa parete (CURZI 1999: 613), è stato di recente datato da Cristina Ranucci alla fine dell'VIII secolo e collegato al resto della decorazione altomedievale di questo ambiente (RANUCCI 2015: 315, tavv. XVII. a1-2).

\footnotetext{
${ }^{28}$ Osborne 1992: 311. Questo saggio, dedicato ai diversi tipi di tessuti e alla loro imitazione in pittura a Roma nell'altomedioevo, resta ancora un punto di riferimento imprescindibile.

${ }^{29}$ Si tratta dei velari appartenenti al primo strato della decorazione della parete per la quale Anna Melograni (1990: 144-145, 158, figg. 4 e 6) ha proposto una datazione entro la metà del VI secolo, che tuttavia non è da escludere possa essere posticipata alla seconda metà del VI secolo o agli inizi del secolo successivo.

${ }^{30}$ Nordhagen 1962: 63; Nordhagen 1978:133, Pl. LVIIa.

${ }^{31}$ Il battistero di San Crisogono, la cui fondazione è pressoché contemporanea a quella di Santa Cecilia, condivideva con quest'ultima anche la rete di canalizzazione dell'acqua, come dimostra l'iscrizione apposta sulla fistula di adduzione trovata durante gli scavi: + pet(---) s(an)c(t)oru(m) Chrys(o)g(oni) et Cec(iliae). Si veda PArmegiani, PRONTI 2007b: 46.
} 
I vela della cappella "H9" sono oggi leggibili sulla parete nord, attraverso le lacune dello strato soprastante di XI secolo, e sulla est, nel registro inferiore, sotto alla figura stante di sant'Agata. ${ }^{32}$ Quest'ultimo drappo è connotato al centro da un motivo floreale a petali e pistilli e anch'esso non presenta le pieghe del panneggio. Per la decorazione del primo strato della cappella, attribuita in passato al 700 circa (KRAUTHEIMER 1952: 21), ho proposto altrove una posticipazione alla fine dell'VIII secolo - prima metà del IX secolo (BoRDI 2007: 215-217). Un'ulteriore conferma della datazione più tarda delle pitture di Santa Cecilia viene, inoltre, dall'osservazione della fascia ornamentale posta tra i vela e la decorazione a riquadri che decorava la parte superiore della parete. Il festone non esibisce quella libertà compositiva e quel naturalismo che caratterizza le ghirlande di fiori e frutta attestati nelle decorazioni, soprattutto musive, di V e VI secolo, come ad esempio i mosaici del sottarco di Santa Maria Maggiore (432-440) ${ }^{33}$ o di quello di San Lorenzo fuori le mura (578-590) (TADDEI 2002: 1763-1788). Esso è invece assai prossimo alle fasce a ghirlanda conservate nella basilica di Santa Prassede, nei sottarchi di due finestre del transetto meridionale (fig. 15), ma anche alla decorazione a festone con gigli e foglie dell'intradosso dell' arco centrale della "trifora" della stessa Santa Cecilia in Trastevere (fig. 27) che Parmegiani e Pronti attribuiscono proprio alla fase di Pasquale I (817-824). ${ }^{34}$ Restando sulla decorazione dei sottarchi della "trifora" ritengo che anche la decorazione del primo arco, che i due archeologi datano al V secolo (Parmegiani, Pronti 2004: 91-92; Iid. 2007b: 47, fig. 63), sia da collegare alla campagna pittorica del tempo di Pasquale I (fig. 28). Anche le semicirconferenze tangenti con cornici perlinate, che caratterizzano questo secondo sottarco, trovano riscontri nel ricco repertorio decorativo della decorazione pittorica e musiva di spazi di risulta, intradossi di finestra e cornici della basilica di Santa Prassede. Tornando ai vela, è stato invece attribuito al tempo di Pasquale I un secondo velario conservato sulla parete meridionale dell'aula, in situazione di palinsesto con quello di cui abbiamo trattato sopra (PARmegiani, Prontr 2007c: 59). I due velari sovrapposti poggiano sulla muratura di una nuova parete laterizia sulla quale si aprono tre feritoie a gola di lupo (Ibid.: figs. 70-76) (figs. 29). Questa parete era stata costruita a chiusura di un ambiente adiacente all'aula, all'interno del quale, secondo l'ipotesi di Parmegiani e Pronti, fu creata una camera per le reliquie. ${ }^{35}$ Del secondo velario, restano due panneggi sul versante occidentale della parete. Si tratta di un tendaggio più alto del precedente e caratterizzato da panneggi stretti attraversati da lunghe pieghe delineate da linee blu scuro (fig. 30). La sua estensione in altezza non sembra accordarsi con la morfologia della parete dal momento che, integrando mentalmente la parte oggi caduta, questa insisterebbe sulla stessa quota delle tre finestre a gola di lupo. Il velario appartenente al primo strato è, invece, molto più basso e sembra concepito nel rispetto in

\footnotetext{
${ }^{32}$ Le pitture della cappella "H9" sono state oggetto nel 2008 di un intervento di restauro da parte della Soprintendenza per i beni architettonici e paesaggistici e per il patrimonio storico-artistico e demoantropologico di Roma, sotto la direzione di Alia Englen.

${ }^{33}$ Vedi da ultimo: Menna 2006: 343-346, figs. 35-36, 46.

${ }^{34}$ Non a caso i due archeologi affermano che questo festone imiti la fascia ornamentale posta a coronamento del velario della parete settentrionale dell'aula. PARMEGiani, Pronti 2007c: 58-59, fig. 73.

${ }^{35}$ La parete è chiamata 79 bis, Parmegiani-Pronti 2007c: 57-58.
} 
altezza dell'apertura delle tre finestre. Il velario più recente, considerato da Parmegiani e Pronti frutto degli interventi di IX secolo nel battistero (Parmegiani, Pronti 2004: 119; Eid. 2007c: 59-60), mostra nondimeno dei caratteri peculiari quali la presenza nel campo superiore di due figure di animali affrontati, delineati in modo piuttosto corsivo in ocra, e nel campo centrale di un motivo di difficile lettura, a carattere ornamentale, delineato in rosso, che inducono a confrontarlo con i vela attestati a Roma tra X e XI secolo. Tra questi, si riconosce una certa familiarità con $\mathrm{i}$ finti drappeggi conservati nell'absidiola nord della chiesa dei Santi Quirico e Giulitta, pertinenti al secondo strato della decorazione (seconda metà del X secolo)(fig. 31), ${ }^{36}$ e quelli appartenenti alla fase della metà dell'XI secolo della cappella "H9" a San Lorenzo fuori le mura (BORDI 2007: 217-222) (fig. 32). Se questi confronti appaiono convincenti, il battistero sarebbe stato oggetto di un ulteriore intervento decorativo a cavallo tra il X e l'XI secolo, prima dell'innalzamento di quota di m. 2,15, avvenuto tra il XII e il XIII secolo (Parmegiani, Pronti 2007c: 60-63).

Tornando alla campagna decorativa della prima fase, se si accoglie la sua posticipazione agli anni del pontificato di Pasquale I, questo intervento potrebbe trovare una valida giustificazione proprio nell'allestimento della camera per le reliquie sul versante meridionale dell'aula (Ibid.: 57-58, fig. 76), dove, l'erezione di una nuova parete dovette necessariamente comportare l'aggiornamento della decorazione dell'intera aula. Rivolgendo poi lo sguardo alle committenze di Pasquale I nell'Urbe, l'acquisizione di questa nuova fase decorativa del battistero, comporterebbe l'esistenza di un ulteriore intervento pittorico voluto dal pontefice, accanto alle ben note imprese musive nelle sue tre basiliche: Santa Prassede, Santa Cecilia in Trastevere e Santa Maria in Domnica. Si tratterebbe di una campagna decorativa parallela e complementare a quanto realizzato in Santa Prassede. Infatti, operando un'osmosi virtuale tra i due contesti, la zoccolatura conservata nel battistero di Santa Cecilia potrebbe aiutare a integrare quanto oggi è andato perduto nel transetto ovest della basilica esquilina. Potremmo allora immaginare che a Santa Prassede i fedeli, dopo aver percorso la cripta semi anulare, risalendo la rampa di scale si sarebbero trovati davanti un'elegante cortina dipinta, chiusa in alto da un rigoglioso fregio classicheggiante con foglie, fiori e frutti, sovrastata, a sua volta, dal corteo stante degli stessi martiri di cui avevano poco prima onorato le reliquie. Al di sopra del corteo, lungo le alte pareti del transetto, lo sguardo si sarebbe poi smarrito nel ripercorrere registro dopo registro le efferatezze dei loro martiri. ${ }^{37}$

\footnotetext{
${ }^{36}$ Si veda da ultimo: Bordi 2006: 315-317.

${ }^{37}$ Vedi supra la ricostruzione del transetto di S. Prassede.
} 
FonTI

Anastasius S. R. Bibliothecarii Historia, de vitis romanorvm pontificvm a b.Petro apostolo vsque ad Nicolavm I. nunquam hactenus typis excusa. Deinde Vita Hadriani II. et Stephani VI. Moguntia, in Typographeio Ioannis Albini, MDCII

Duchesne, Louis; Vogel, Cyrille, 1955 (Eds.). Le Liber pontificalis : texte, introduction et commentaire. Paris : E. de Boccard.

VASARI, Giorgio, 1986 [1550]. Le Vite de' piú eccellenti architetti, pittori et scultori italiani, da Cimabue, insino a'tempi nostri. Nell'edizione per i tipi di Lorenzo Torrentino, Firenze 1550, L. Bellosi, A. Rossi, (Eds.), Torino, Giulio Einaudi editore. http://www.letteraturaitaliana.net/pdf/ Volume_5/t129.pdf

Gregorovius, Ferdinand, 1973 [1903]. Storia della città di Roma nel medioevo, W. Kampf(Ed.), Torino, Giulio Einaudi.

\section{Bibliografia}

Andaloro, Maria, 1987. “Aggiornamento scientifico”, G. Matthiae, 1987 [1965]. Pittura romana del Medioevo, secoli IV-X, M. Andaloro (Ed.), Roma, Fratelli Palombi Editori.

-2006a (Ed.). La Pittura medievale a Roma: 312-1431. Atlante, percorsi visivi, Viterbo-Milano, Università della Tuscia-Jaca Book.

-2006b (Ed.). L'orizzonte tardoantico e le nuove immagini. 312-468, La Pittura medievale a Roma: 312-1431. Corpus I, Milano, Jaca Book

Andaloro, Maria; Bordi, Giulia; Morganti, Giuseppe, 2016 (Eds.). Santa Maria Antiqua tra Roma e Bisanzio. Roma, basilica di Santa Maria Antiqua al Foro romano, rampa imperiale. 17 marzo-11 settembre 2016, Roma-Milano, Ministero dei Beni e delle Attività Culturali»

Apollonj-Ghetti, Bruno Maria, 1961. Santa Prassede, Roma, Le chiese di Roma illustrate, Marietti.

Armellini, Mario, 1887. Le chiese di Roma dalle loro origini sino al secolo XVI, Roma Tipografia Editrice Romana.

Bertelli, Carlo, 1983. “Traccia allo studio delle fondazioni medievali dell'arte italiana”, Storia dell'arte italiana. Parte seconda, Dal Medioevo al Novecento. Volume primo, Dal Medioevo al Quattrocento, Torino: G. Einaudi: 5-163. 
Bordi, Giulia, 2006. “Santi Quirico e Giulitta”, Andaloro, Maria, 2006a (Ed.): 315-318.

-2007. “Crescentius, un infelix pictor dell'VIII secolo? Nuove proposte di datazione per un gruppo di dipinti romani", S. Romano, J. Enckell Julliard (Eds.), Roma e la Riforma gregoriana. Tradizioni e innovazioni artistiche (XI-XII secolo), Roma, Viella: 213-246.

-2008. Gli affreschi di San Saba sul piccolo Aventino. Dove e come erano. Milano, Jaca Book. -2009a. "Giuseppe Wilpert e la scoperta de la pittura altomedievale a Roma", S. Heid (Ed.), Giuseppe Wilper archeologo cristiano. Atti del convegno, Roma 16-17 maggio 2007, Città del Vaticano, Pontificio Istituto di Archeologia cristiana: 323-358.

-2009b. "Copie, fotografie, acquerelli. Documentare la pittura medievale a Roma tra Otto e Novecento",A. C. Quintavalle (Ed.), Medioevo: immagine e memoria, Atti del l'XI Convegno Internazionale di Studi (Parma, 23-28 settembre 2008) (pp. 454-462), Bologna, Electa: 454-462. -2015. "Tra pittura e parete: palinsesti, riusi e obliterazioni nella diaconia di Santa Maria in Via Lata tra VI e XI secolo”, A. Molinari, R. Santangeli Valenzani, S. Lucrezia (Eds.), L'archeologia della produzione a Roma (secoli $V$-XV), Roma, École française de Rome: 395-410.

-2016. "Dall'Oratorio dei Quaranta Martiri a Santa Maria de inferno", Andaloro, Maria; Bordi, Giulia; Morganti, Giuseppe, 2016 (Eds.): 278-287.

CANCELlieri, Francesco, 1806. Le due nuove campane di Campidoglio benedette dalla sua santità di N. S. Pio VII. P. O. M. e descritte da ... con varie notizie sopra i campanili e sopra ogni sorta di orologi ed un appendice di monumenti, Roma, Antonio Fulgoni.

CAPERna, Maurizio, 1999. La Basilica di Santa Prassede. Il significato della vicenda architettonica, Genova, Edizioni d'arte Marconi.

—, 2014. La Basilica di Santa Prassede. Il significato della vicenda architettonica, nuova edizione rivista e aggiornata, Roma, Edizioni Quasar.

CurzI, Gaetano, 1999. "La decorazione medievale oratorio del c.d. del Ss. Salvatore sotto la basilica dei Ss. Giovanni e Paolo", A. Cadei et alii (Eds.), Arte d'Occidente. Studi in onore di Angiola Maria Romanini. Temi e metodi, Roma, Edizioni Sintesi Informazione: 607-616.

Falla-Castelfranchi, Marina (2011). "A chi era dedicata in origine la chiesa detta di Santa Passera?”, W. Angelelli, F. Pomarici (Eds.), Forme e storia, scritti di arte medievale e moderna per Francesco Gandolfo, Roma, Artemide: 73-77.

Finocchio, Giuseppe, 2010. "Riflessioni sul pavimento presbiteriale della chiesa di S. Prassede (Roma)", C. Angelelli, C. Salvetti (Eds.), Atti del XV Colloquio dell'Asociazione Italiana per lo Studio e la Conservazione del Mosaico (Aquileia 4-7 febbraio 2009), Tivoli, Scripta Manent edizioni: 305-314. 
Germano di San Stanislao, 1894. La casa Celimontana dei Ss. Martiri Giovanni e Paolo, Roma, Tip. Della Pace di F. Cuggiani.

Goodson, Caroline, 2010. The Rome of Pope Paschal I: Papal Power, Urban Renovation, Church Rebuilding and Relic Translation, 817-824, Cambridge, Cambridge University Press.

Guidobaldi, Federico, 1997. "Gli scavi del 1993 - 95 nella basilica di S. Clemente a Roma e la scoperta del battistero paleocristiano: nota preliminare", Rivista di archeologia cristiana, 73: 459-491.

Gulowsen, Kirstin, 1994. The Frescoes of the Oratory of the Forty Martyrs. Forum Romanum (Dissertation), University of Oslo 1994.

Jessop, Lesley, 1999. "Pictorial cycles of non-biblical saints: the seventh-and eighth-century mural cycles in Rome and contexts for their use", Papers of the British School at Rome, 67: 233-280.

Krautheimer, Richard, 1952. "San Lorenzo fuori le mura in Rome. Excavations and Observations", Proceedings of the American Philsophical Society, 96, 1: 1-26.

-1981. Roma: profilo di una città, 312-1308, Roma, Edizioni dell'Elefante.

Krautheimer, Richard; Corbett, Spencer; Dienstfrei, Debra, 1971. "Santa Prassede", Corpus basilicarum christianarum Romae: le basiliche cristiane antiche di Roma (sec. IV-IX), vol. III, Città del Vaticano: 235-262. [1 $1^{\mathrm{a}}$ edizione in inglese 1967]

MAnaCorda, Simona, 1994. "La chiesa di Santa Passera a Roma e la sua decorazione pittorica medievale”, Bollettino D'Arte, 88: 35-58.

Mancho, Carles, 2011. "Pasquale I, santa Prassede, Roma e Santa Prassede", Arte Medievale, IV Serie, I Anno, 2010-2011: 31-48.

-2016. "Pascal Ier : autorité pontificale et création artistique à Rome au début du IXe siècle. Quelques notes.", A.-O. Polipré (Ed.), Faire et voir l'autorité pendant l'Antiquité et le Moyen Age. Images et monuments, actes de la journée d'étude tenue à Paris le 14 novembre 2014 à Institut National d'Histoire de l'Art, Paris, Université Paris 1 Panthéon-Sorbonne; Centre de recherche HiCSA: 71-96. [http://hicsa.univ-paris1.fr/documents/pdf/PublicationsLigne/JE\%20 Poilpre\%20Autorite\%202016/04_Mancho.pdf]

Mango, Cyril, 1972. The Art of the Byzantine Empire, 312-1453 : Sources and Documents, Toronto, University of Toronto Press in association with the Medieval Academy of America. 
Melograni, Anna, 1990. "Le pitture del VI e VII secolo nella basilica inferiore di S. Crisogono in Trastevere", Rivista dell'Istituto Nazionale d'Archeologia e Storia dell'arte, S. III, XIII:139-178. Menna, Maria Raffaella, 2006. "I mosaici della basilica di Santa Maria Maggiore. Il titulus dedicatorio sulla controfacciata e il mosaico della perduta abside", Andaloro, Maria, 2006b (Ed.) : 343-346.

Minasi, Mara, 2009. La tomba di Callisto appunti sugli affreschi altomedievali della cripta del papa martire nella catacomba di Calepodio, Città del Vaticano, Pontificia commissione di archeologia sacra.

Mortari, Luisa, 1969. "Secolo IX-Storie di Martiri”, G. Matthiæ (Ed.), Attività della Soprintendenza alle Gallerie del Lazio. XII settimana dei Musei. Sala di Santa Marta. Roma, 1327 aprile 1969, Roma, Ministero dellaPubblica Istruzione-Direzione Generale Antichità e Belle Arti: 9-10.

MuÑoz, Antonio, 1918. "Studio sulle basiliche romane di Santa Sabina e Santa Prassede" Dissertazioni della Pontificia Accademia Romana di Archeologia, 13: 117-128.

NARdoni, Leone, 1870. L' antico oratorio di Sant'Agnese in Monasterio con pitture cristiane del secolo nono. Roma, Topografia di G. Aurelj.

NesBitt, Alexander, 1866. "On the Churches at Rome earlier than the year 1150", The Archoeologia, 40: 157-224.

Nordhagen, Per Jonas, 1962. "The earliest Decorations in Santa Maria Antiqua and their Date", Acta ad archaeologiam et artium historiam pertinentia, I: 53-72.

-1978. "S. Maria Antiqua. The Frescoes of the Seventh Century", Acta ad archaeologiam et artium historiam pertinentia, VIII: 89-142.

Osborne, John, 1987. “The atrium of S. Maria Antiqua. Rome. A history in art”, Papers of the British School at Rome, 55: 186-223.

-1992. "Textiles and their painted imitations in early medieval Rome", Papers of the British School at Rome, 60: 309-351.

Parmegiani, Neda; Pronti, Alberto, 2004. S. Cecilia in Trastevere. Nuovi scavi e ricerche. Monumenti di Antichità Cristiana, II Serie, XVI, Città del Vaticano, Pontificio Istituto di Archeologia Cristiana.

—2007a. "L'area archeologica del periodo Classico", C. La Bella et alii (Eds.), Santa Cecilia in Trastevere, Roma, Palombi Editori: 11-40. 
—2007b. "Il titulus Sanctae Caeciliae e il suo battistero", C. La Bella et alii (Eds.), Santa Cecilia in Trastevere, Roma, Palombi Editori: : 41-56.

-2007c. "Le ristrutturazioni del battistero nel Medioevo", C. La Bella et alii (Eds.), Santa Cecilia in Trastevere, Roma, Palombi Editori: : 57-64.

Pennesi, Stefania, 1998. La decorazione altomedievale pittorica del transetto della basilica di Santa Prassede, Tesi di Laurea, Università degli di Chieti "G. d'Annunzio", anno accademico 1997/1998, inedita (consultabile presso l'archivio di S. Prassede).

-2006. "Santa Prassede", Andaloro, Maria (Ed.), 2006: 297-306.

Petriaggi, Roberto, 1984. "Utilizzazione, decorazione e diffusione dei tessuti nei corredi delle basiliche cristiane secondo il Liber Pontificalis (514-795)", Prospettiva, 39, settembre: 37-45.

Ranucci, Cristina, 2015. "L'oratorio medievale". A. Englen et alii (Eds.), Caelius II: Le case romane e i Santi Giovanni e Paolo al Celio. Tomo I, Pars inferior. Il complesso archeologico, Roma, L'Erma di Bretschneider: 309-321.

Romanelli, Pietro; Nordhagen, Per Jonas, 1964. S. Maria Antiqua. Roma, Istituto poligrafico e zecca dello stato.

TADDEI, Alessandro, 2002. "La decorazione dell'intradosso dell'arco trionfale della basilica di S. Lorenzo fuori le Mura", F. Guidobaldi, A. Guiglia Guidobaldi (Eds.), Ecclesiae urbis, atti del congresso internazionale di studi sulle chiese di Roma (IV - X secolo); Roma, 4 - 10 settembre 2000, Città del Vaticano, Pontificio Istituto di Archeologia Cristiana, 3: 1763-1788.

Thunø, Erik, 2014. The apse mosaic in early medieval Rome: time, network, and repetition, New York, Cambridge University Press.

Toesca, Pietro, 1927. Storia dell'arte italiana, I. Il medioevo, Torino, Unione Tipografico editrice Torinese.

WilPERT, Joseph, 1908. "Malereien im Querschiff der Basilika der Hl. Praxedis", Römische Quartalschrift für christliche Altertumskunde und Kirchengeschichte, 22: 177-181.

-1916. Die römischen Mosaiken und Malereien der kirchlichen Bauten vom IV. bis XIII. Jahrhundert, Freiburg im Breisgau, Herdersche Verlagshandlung. 


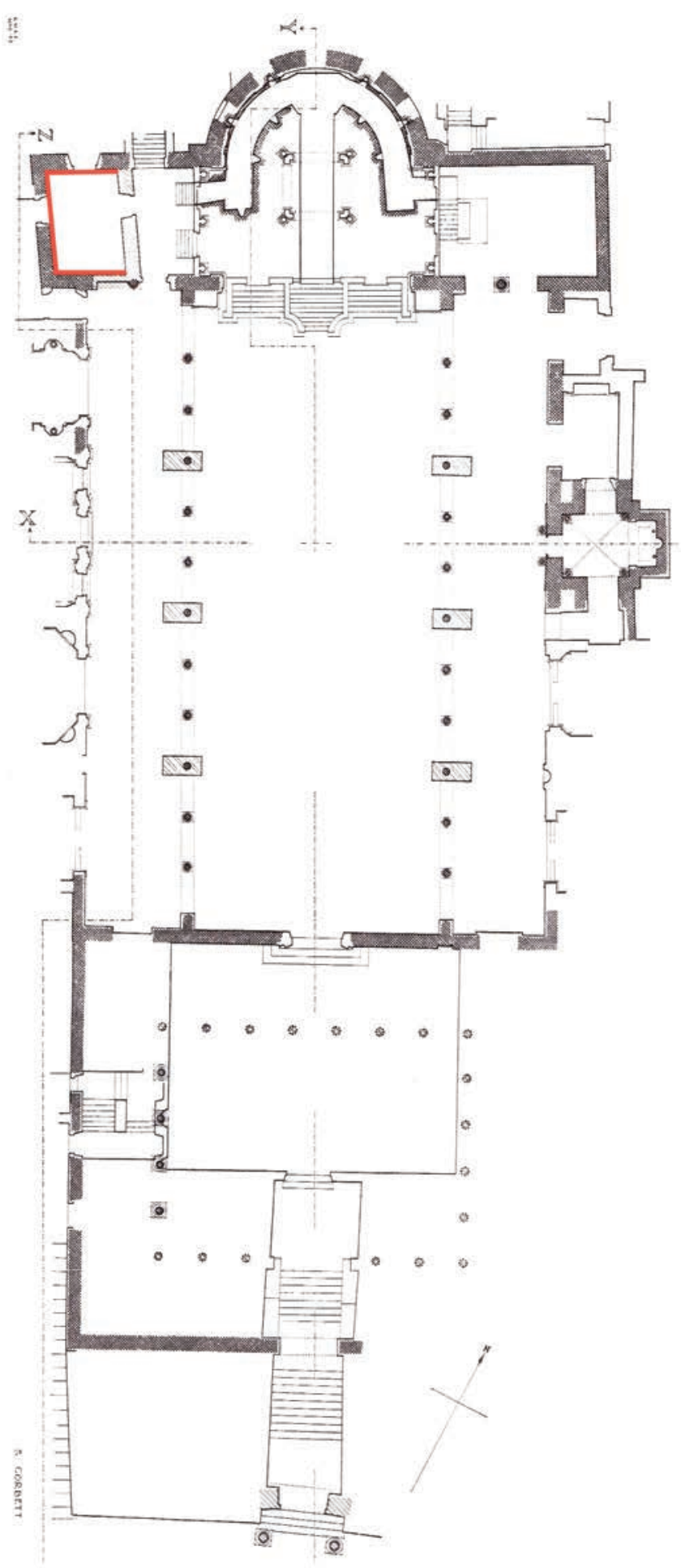

Fig. 1 Pianta di S. Prassede secondo S. Corbett (1971), e riprodotta da R. Wisskirchen (1990, lam. 1). In rosso i muri dove si conservano gli affreschi. (ArxiuCMancho). 

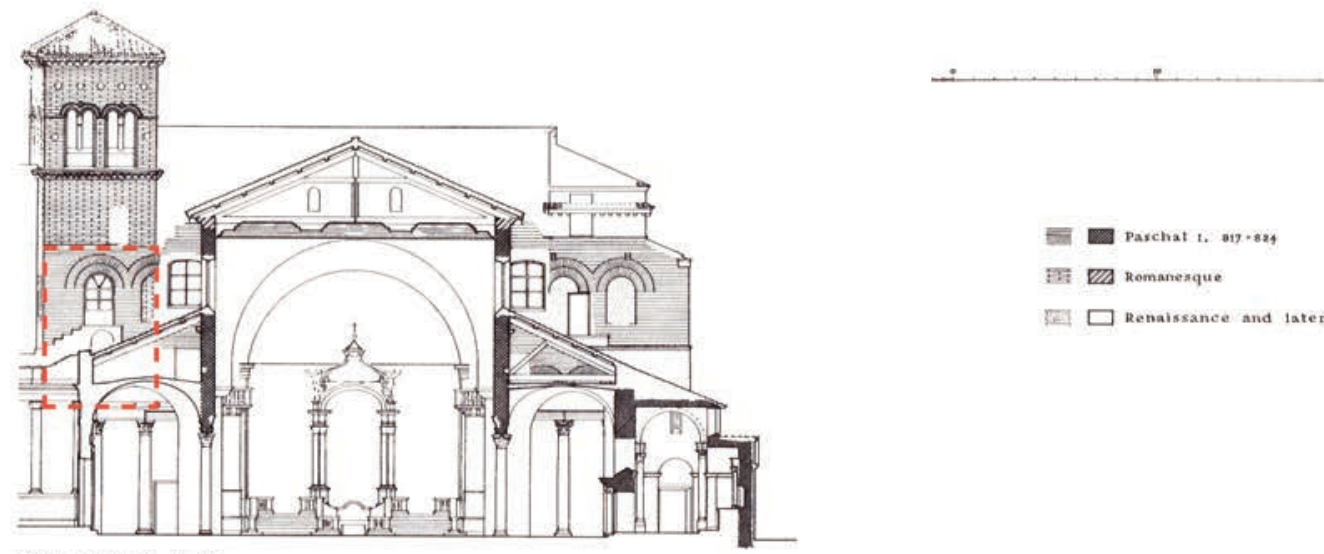

Cross Section $\mathrm{X}-\mathrm{X}$
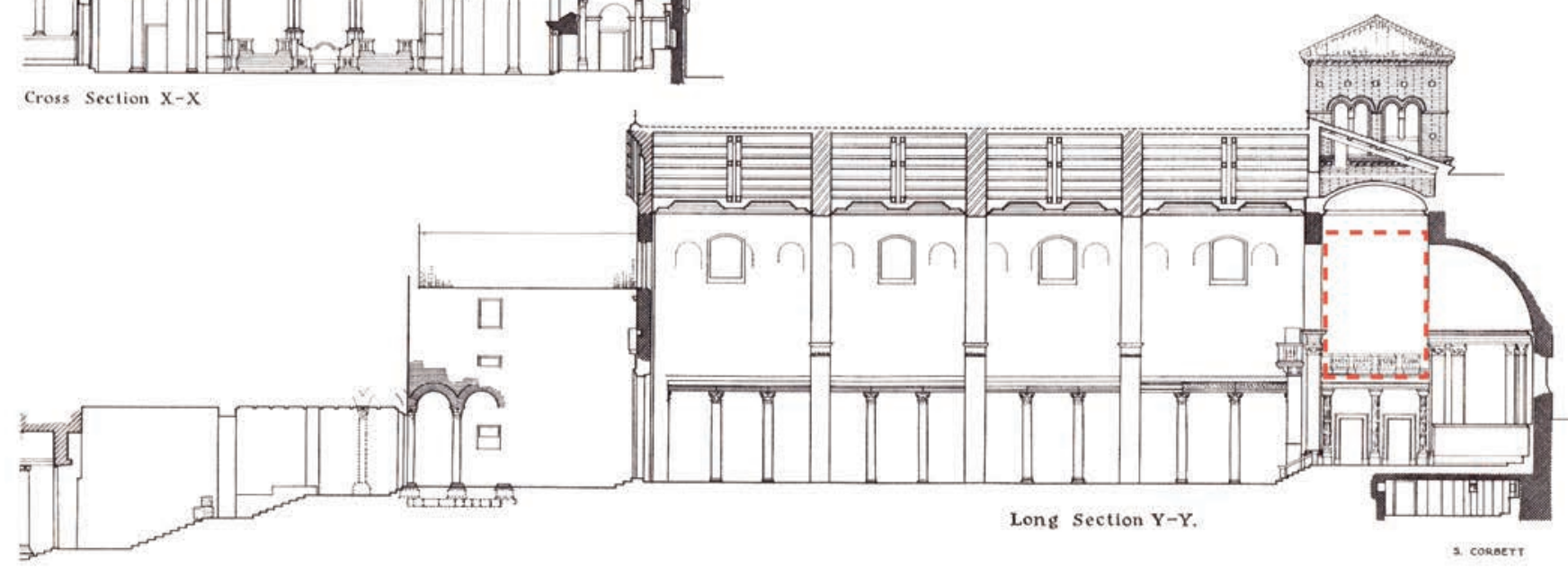

Fig. 2 Sezioni longitudinale (y-y') e trasversale (x-x’) secondo S. Corbett (1971), e riprodotte da R. Wisskirchen (1990, lam. 2). In rosso tratteggiato indichiamo la situazione degli affreschi dentro al campanile già transetto (ArxiuCMancho).
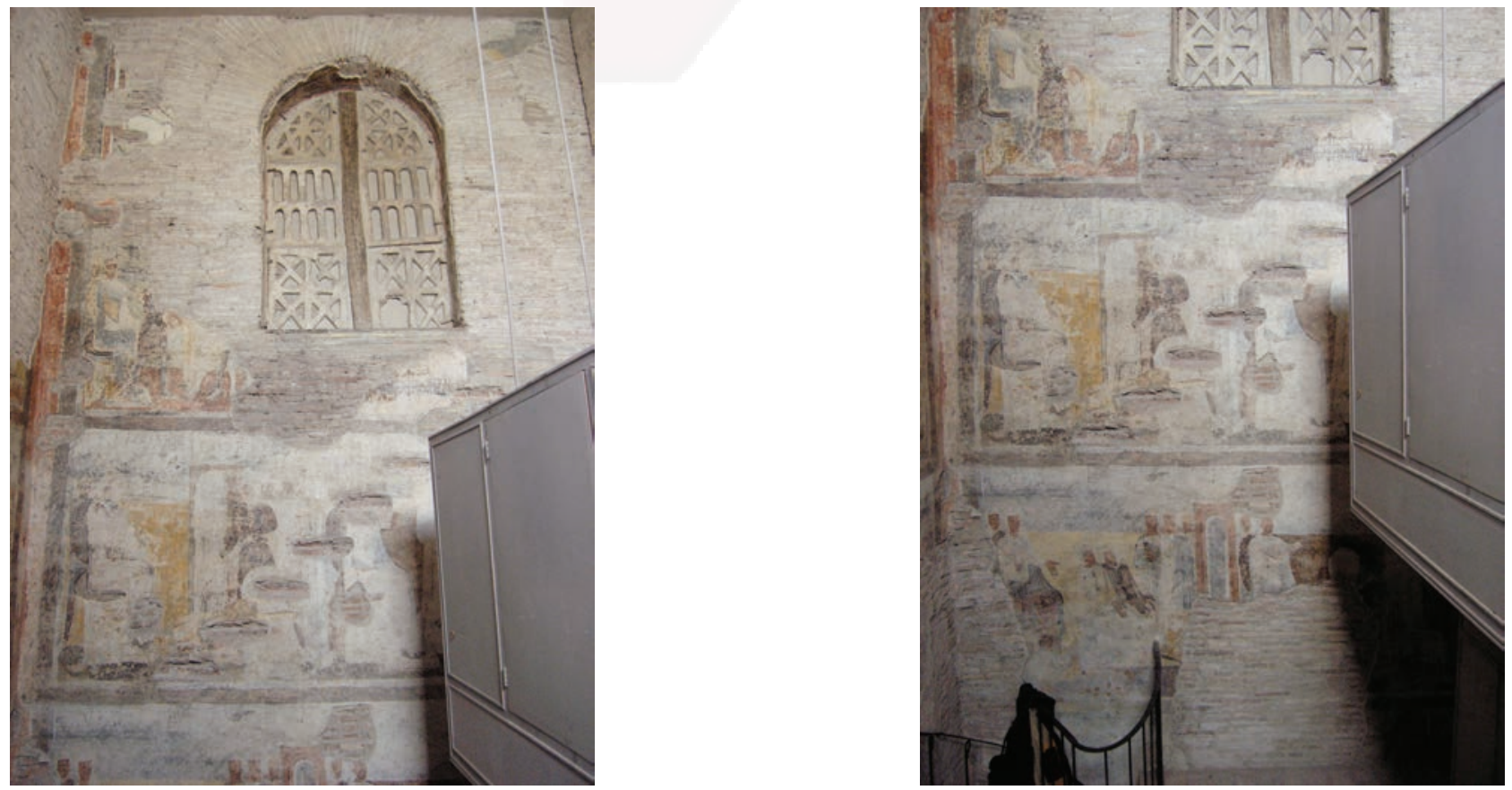

Figg. 3a, 3b Parete nord dell'interno del campanile, già transetto, di S. Prassede dove si possono vedere le pitture conservate, stato al 2005 (ArxiuCMancho). 


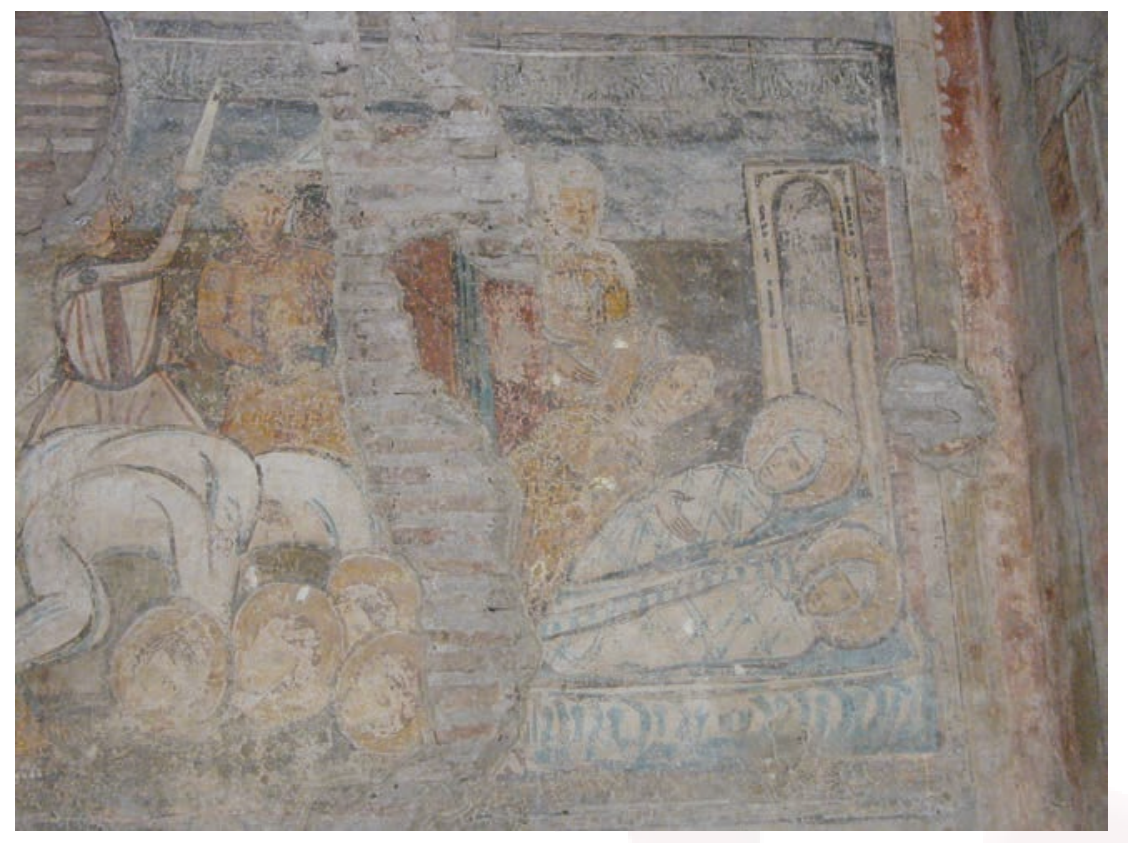

Fig. 4 Particolare della parete sud, registro 3 a, scene 2-3, morte dei figli di Claudio e Ilaria, Giasone e Mauro, e settanta soldati, stato al 2005 (ArxiuCMancho).

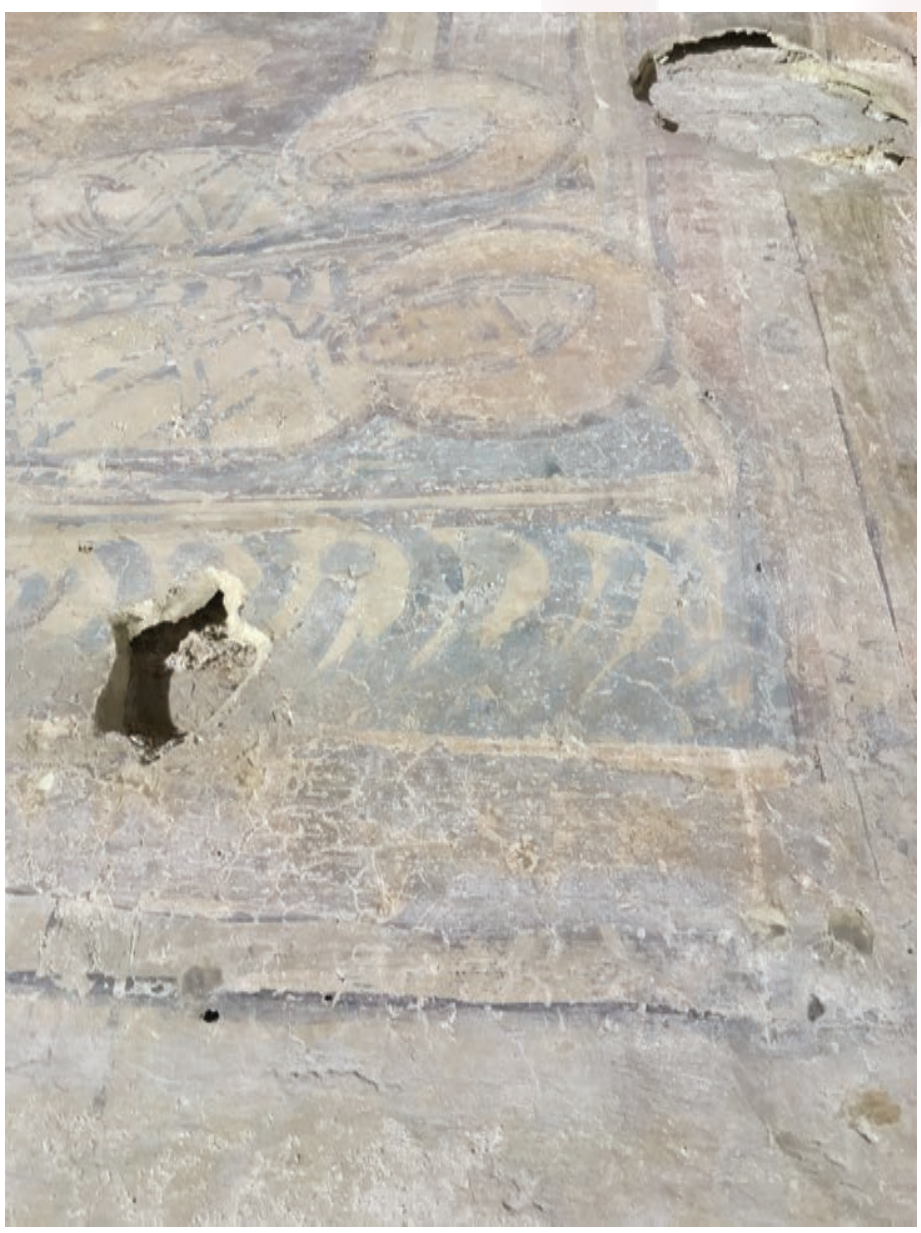

Fig. 5 Particolare della scena precedente, stato novembre 2016, dove si può vedere lo staccamento dal muro (ArxiuCMancho). 


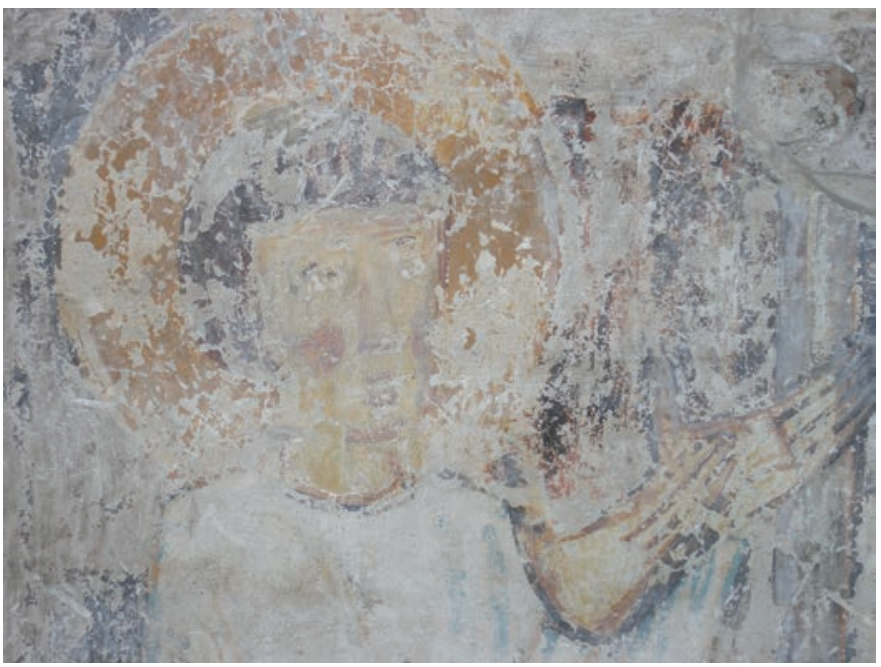

Fig. 6 Particolare del Registro 3 b, scena 1 Crisanto prega dal carcere Tulliano, stato al 2005 (ArxiuCMancho).

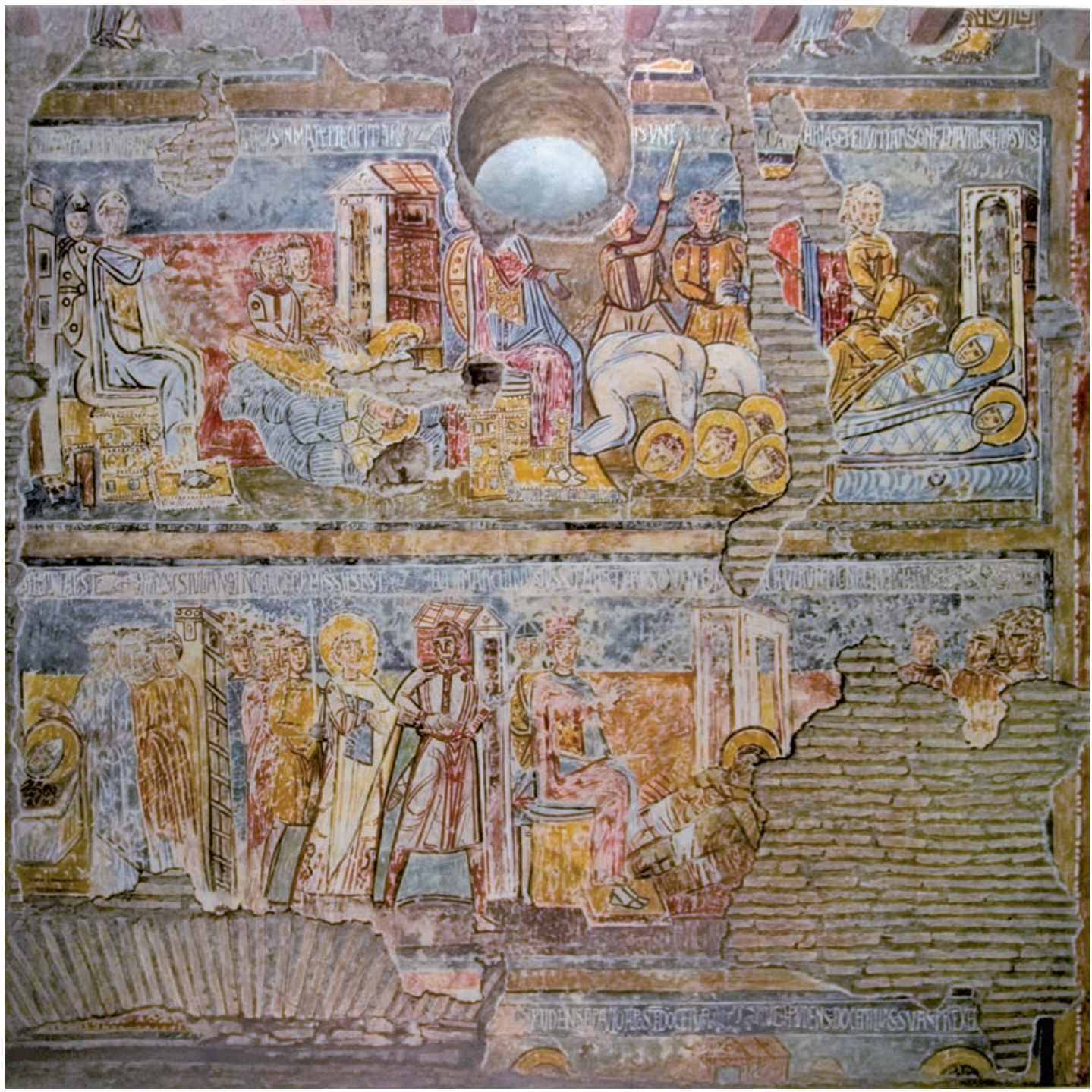

Fig. 7 Affreschi nel muro sud del transetto, secondo le fotografie acquarellate di J. Wilpert (1916: IV, 202). 


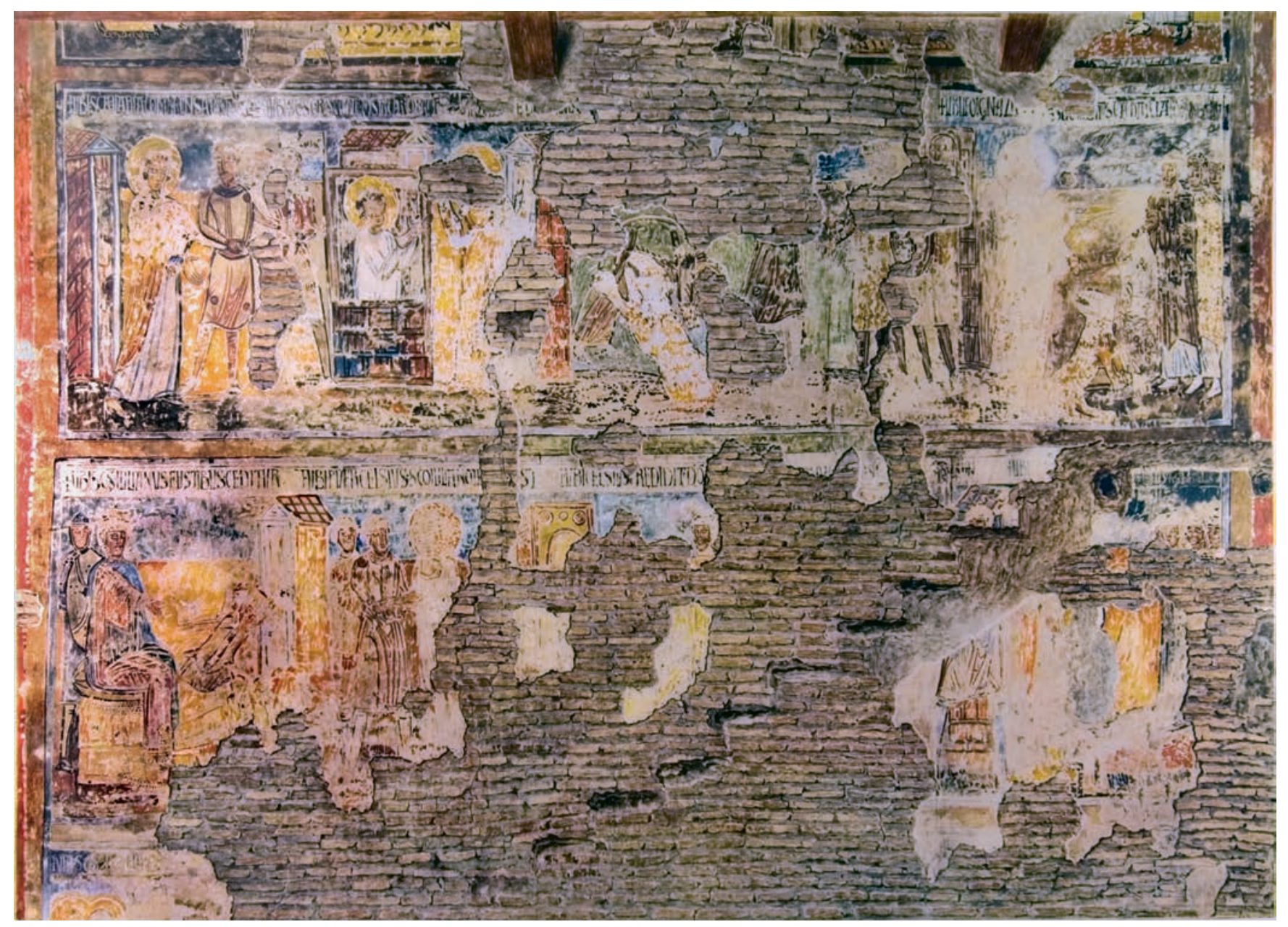

Fig. 8 Affreschi nel muro ovest del transetto, secondo le fotografie acquarellate di J. Wilpert (1916: IV, 204). 


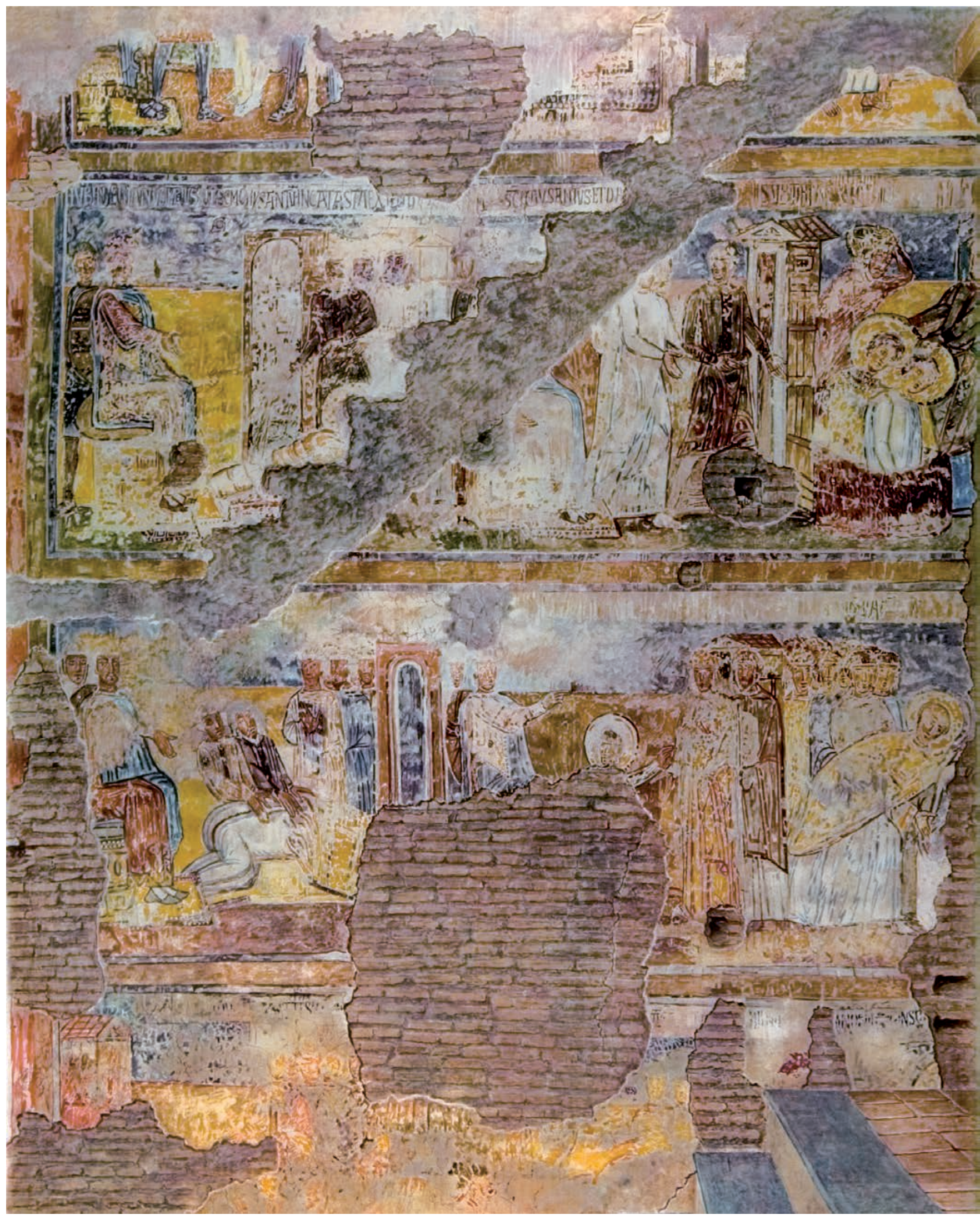

Fig. 9 Affreschi nel muro nord del transetto, secondo le fotografie acquarellate di J. Wilpert (1916: IV, 203). 


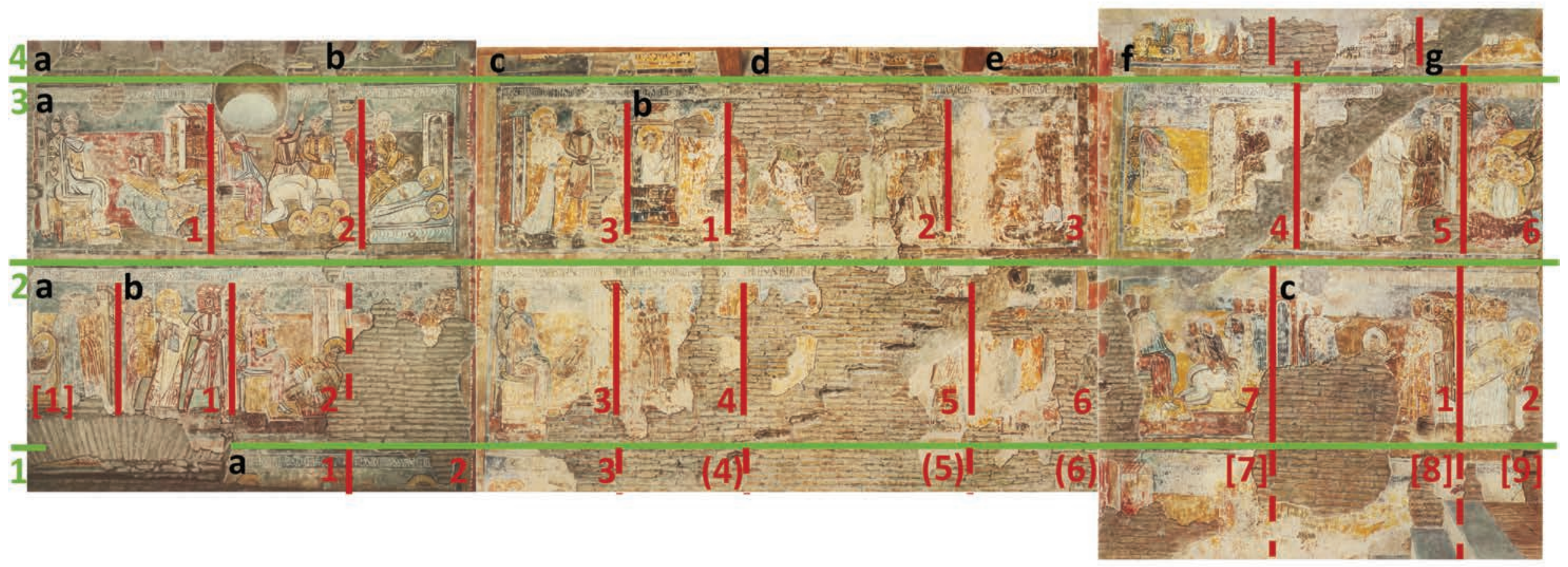

Fig. 10 Identificazione delle scene secondo Pennesi (1998). L'organizzazione in Registri/Cicli/Scene è nostra, così come l'ipotesi di scene nei registri 1 e 4 . I testi fra parentesi indicano le identificazioni non basate sulle iscrizioni dipinte; i numeri fra parentesi tonde indicano possibili scene; i numeri fra parentesi quadre indicano un numero di scena ipotetico:

Registro 4: cicli/scene a-f senza identificazione (s/i)

Registro 3: a ciclo dei martiri Claudio e Ilaria: 1 Claudio condannato da Numeriano; 2 morte dei figli Giasone e Mauro più settanta soldati; 3 Ilaria seppellisce i figli; 4 Ilaria viene arrestata. b ciclo dei martiri Crisanto e Daria: 1 Crisanto prega dal carcere Tulliano; 2 (Daria nel postribolo salvata dal leone); 3 (Daria e il leone salvati dal fuoco); 4 supplizio di Crisanto "in catasta"; 5 Crisanto e Daria condotti al martirio; 6 Morte dei santi Crisanto e Daria.

Registro 2: a ciclo di santa Basilissa: [1] seppellimento di Basilissa. b ciclo dei santi Giuliano e Celso: 1 Giuliano viene arrestato; 2 i compagni di Giuliano vengono bruciati; 3 Giuliano è fustigato; 4 incontro di Giuliano e Celso; 5 conversione di Celso; 6 Celso butta libri e toga; 7 Giuliano e Celso nei barili di pece, bitume e zolfo. c ciclo di Marcionilla e Antonio e il neofito Anastasio, martiri di Antinopoli: 1 Celso indica Marcionilla; 2 battesimo di Marcionilla.

Registro 1: a ciclo dedicato alle sante Prassede e Pudenziana: 1 Pudens indottrinato da san Paolo; 2 Pudens educa le figlie Pudenziana e Prassede; 3 s/i; (4 a 6) perse; 7 a 9 s/i. 


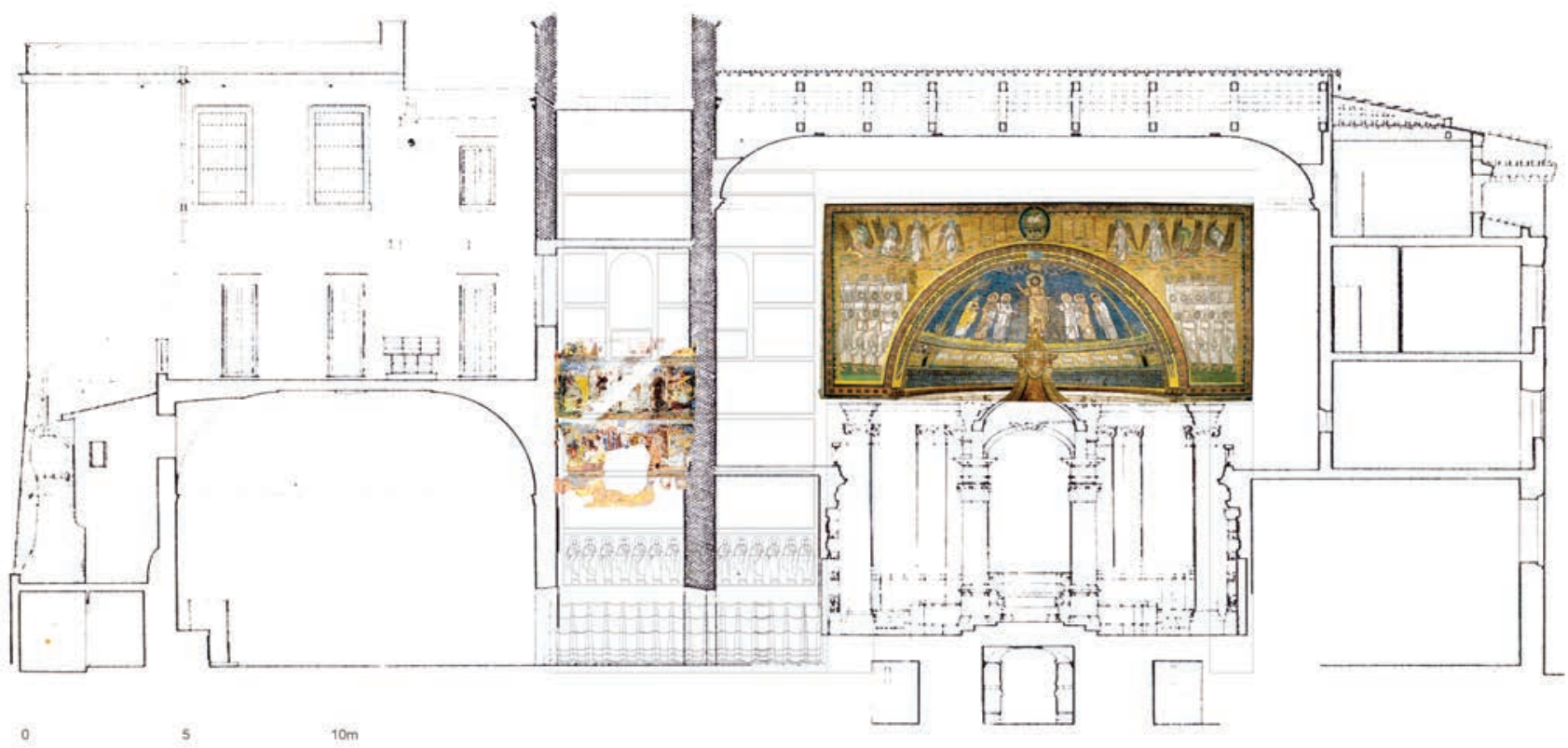

Fig. 11 Ipotesi ricostruttiva di V. Valentini sulla sezione trasversale del presbiterio (fonte: Dahdah, Kabalan, Lettura delle tecnologie storiche della basilica di S. Prassede in Roma e problemi statici di conservazione, Facoltà di Architettura, Sapienza - Università di Roma, relatore prof. A. Giuffré, correlatore prof. V. Ceradini, 1990-1991: tav. 6).
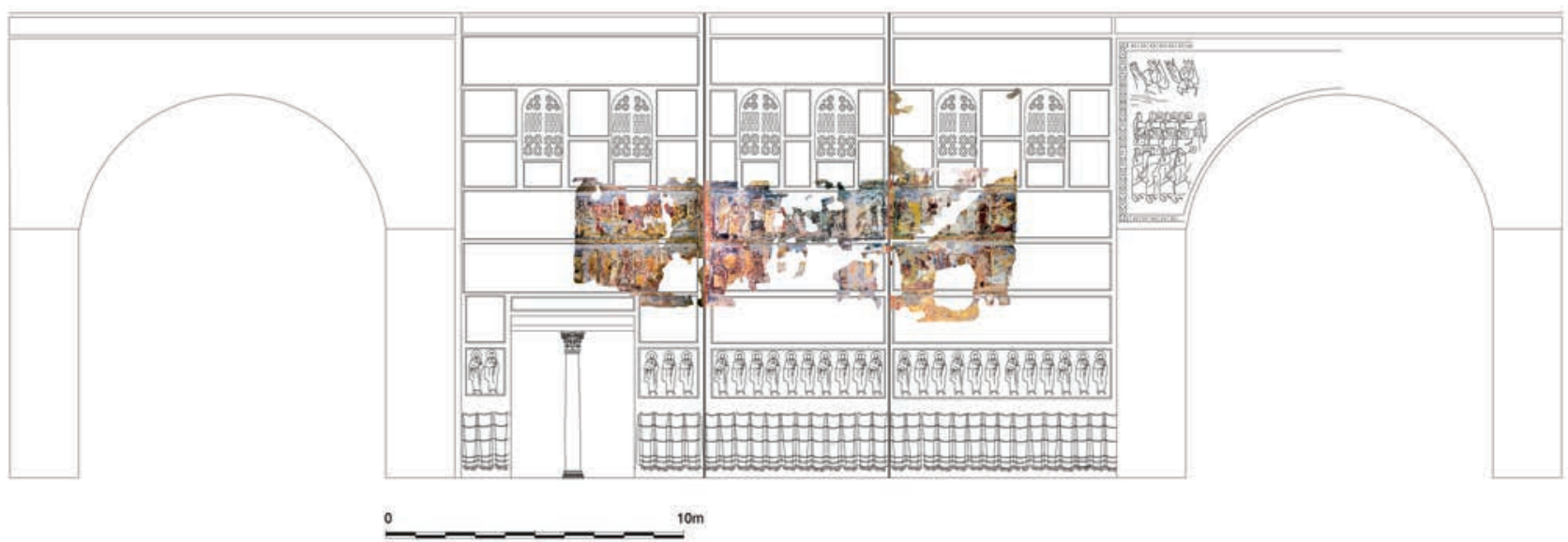

Fig. 12 Ipotesi ricostruttiva con il braccio ovest del transetto sdoppiato, la posizione degli affreschi conservati e il rapporto fra affreschi e mosaici dell'arco absidale. Le dimensioni del braccio ovest del transetto sono: altezza 15,06 m, larghezza 8,68 / 6,04 / 8,14 m. La superficie totale -escluse le aperture- è di $303 \mathrm{mq}$; conserviamo soltanto 52,73 mq affrescati. Secondo l'ipotesi, la decorazione si organizzava in sei registri sovrapposti con scene martiriali con alla base una teoria di martiri sotto alla quale un livello con finte tende dipinte (V. Valentini). 
Fig. 13 Particolare con gli affreschi conservati nel registro 5 a destra della finestra del muro nord. (ArxiuCMancho).
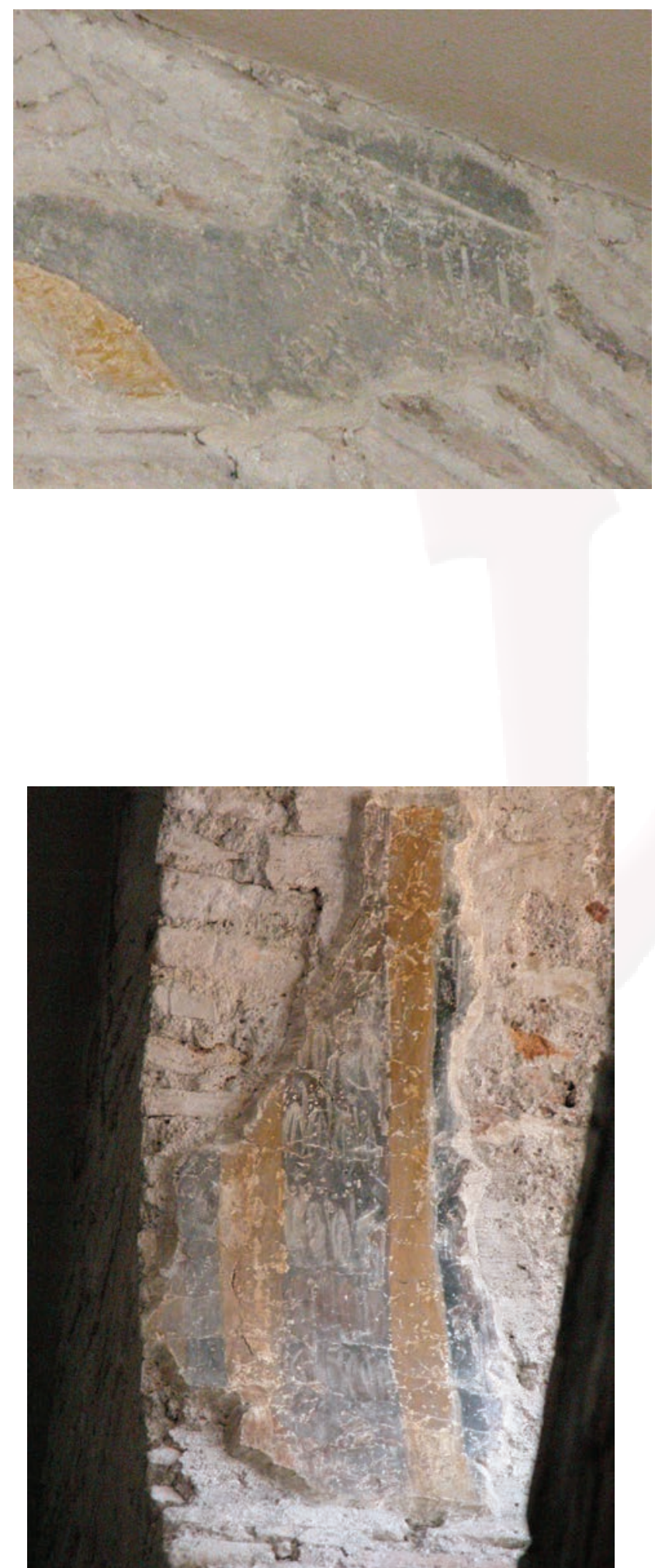

Fig. 15 Particolare dell'intradosso della finestra sud del campanile, già transetto, stato al 2005 (ArxiuCMancho).
Fig. 14 Iscrizione in memoria della traslatione dei 2.300 corpi di martiri e della consacrazione della basilica (ArxiuCMancho).

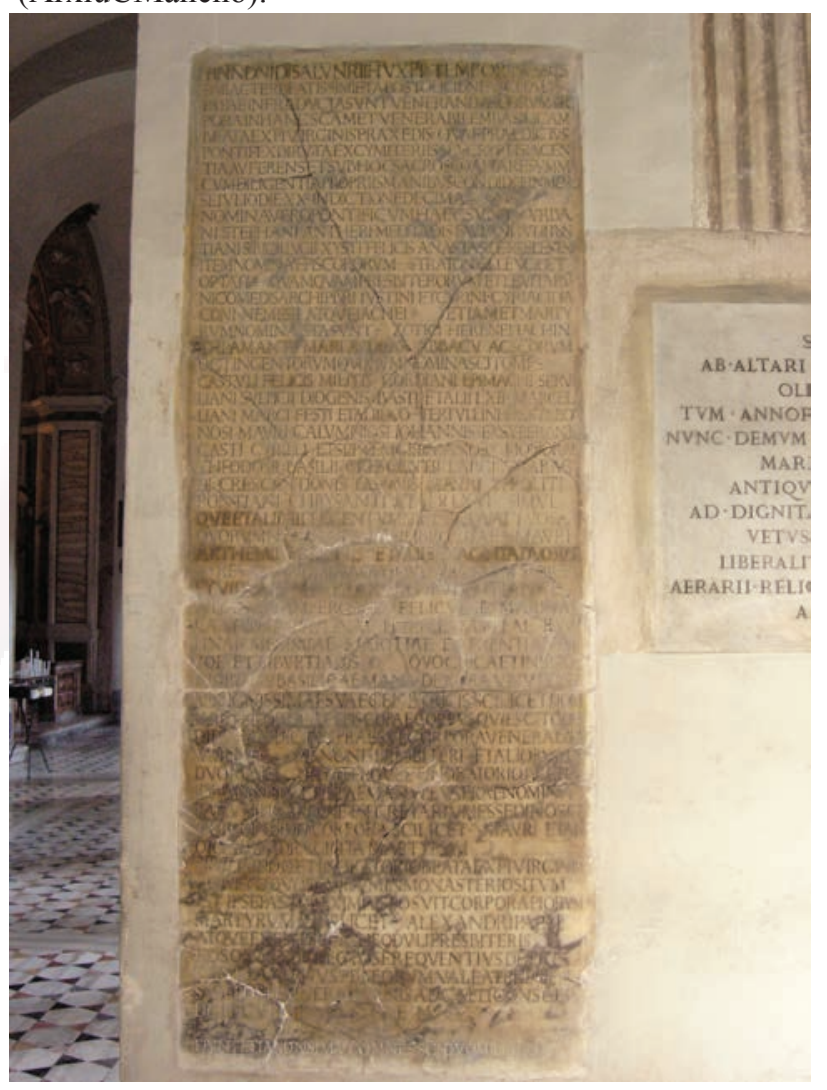




\section{$\boldsymbol{V}$}

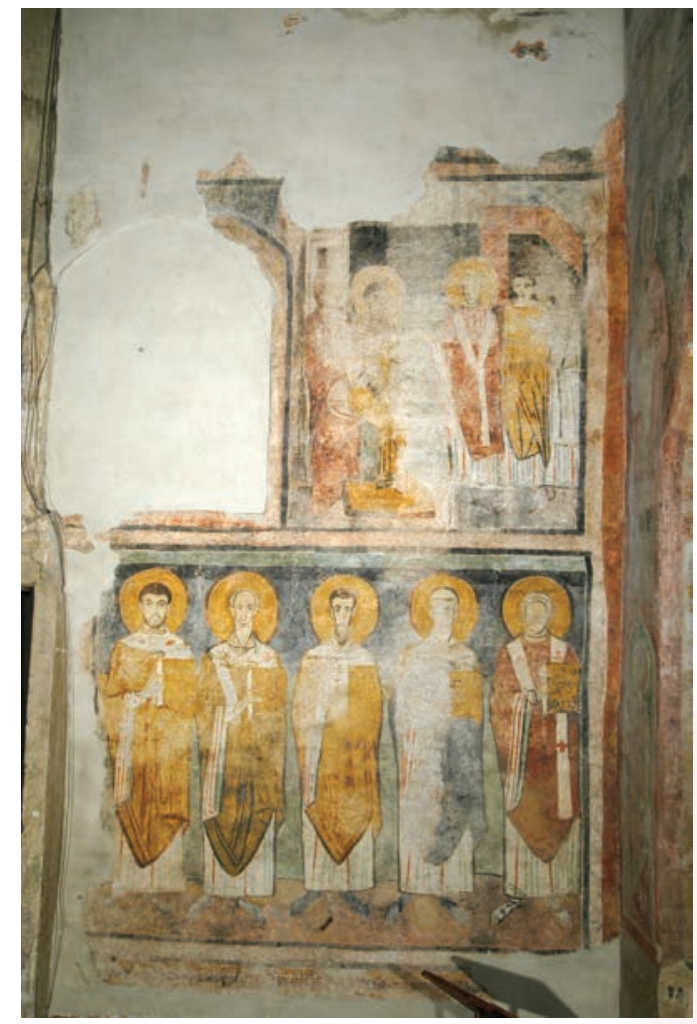

Fig. 16 S. Passera alla Magliana, parete sud, scene della vita di santa Prassede (?) e Padri della Chiesa (Atlante 2006).

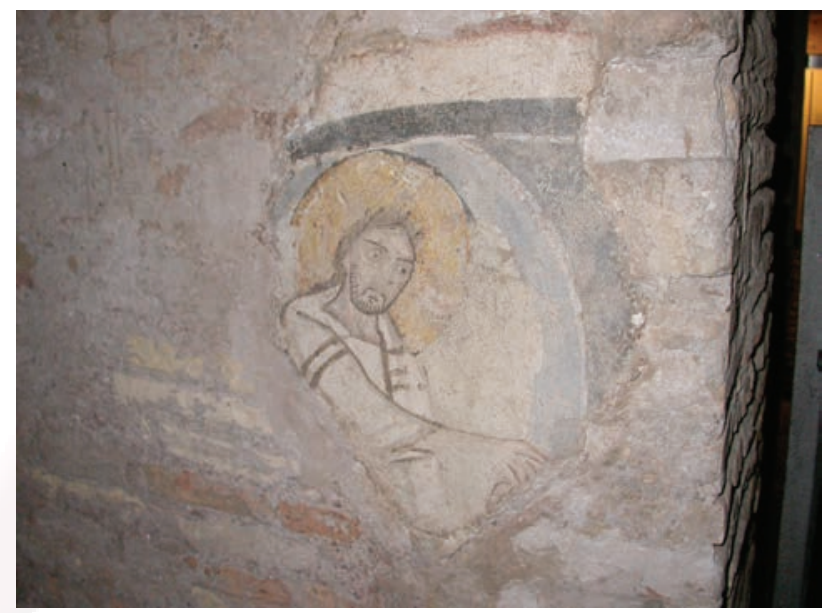

Fig. 17 Oratorio medievale sotto la basilica dei Ss. Giovanni e Paolo, scene cristologiche, particolare dell'Anastasis (G. Bordi).

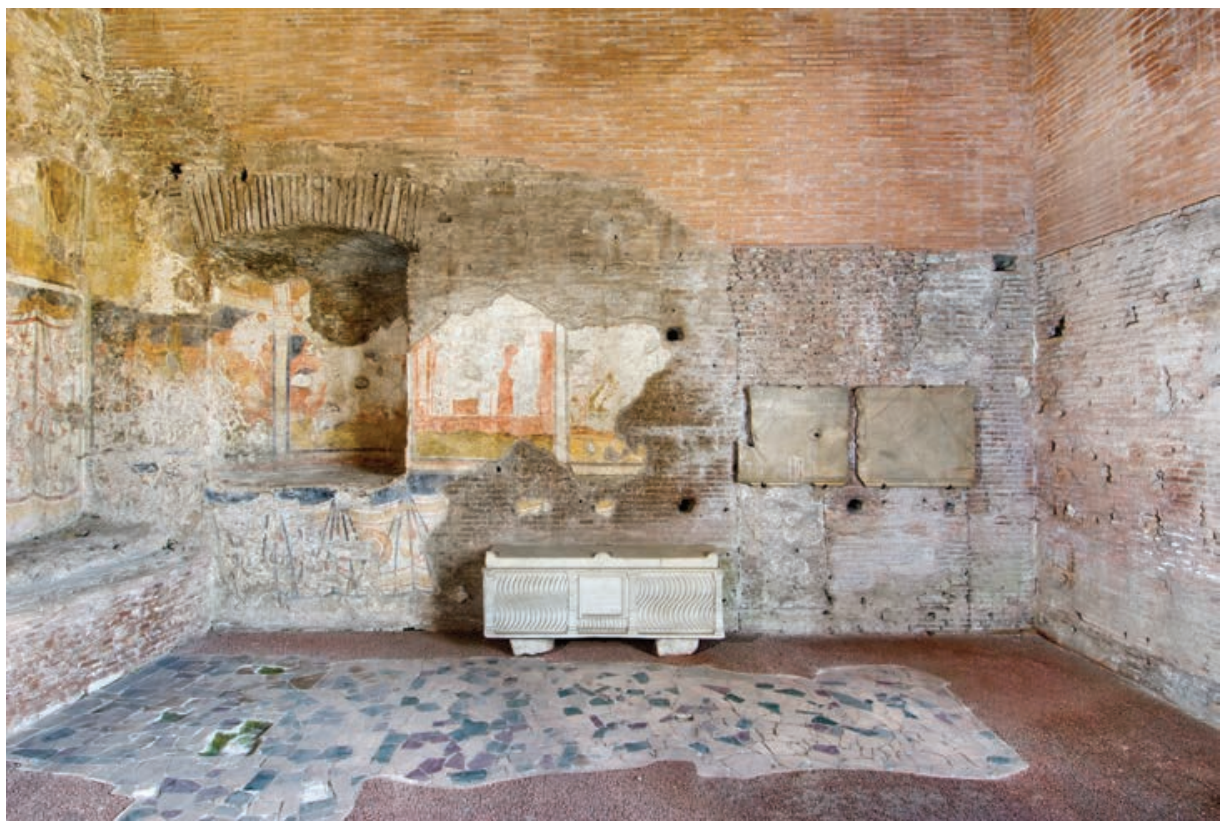

Fig. 18 Oratorio dei Quaranta martiri al Foro romano, parete sud (G. Alfano). 


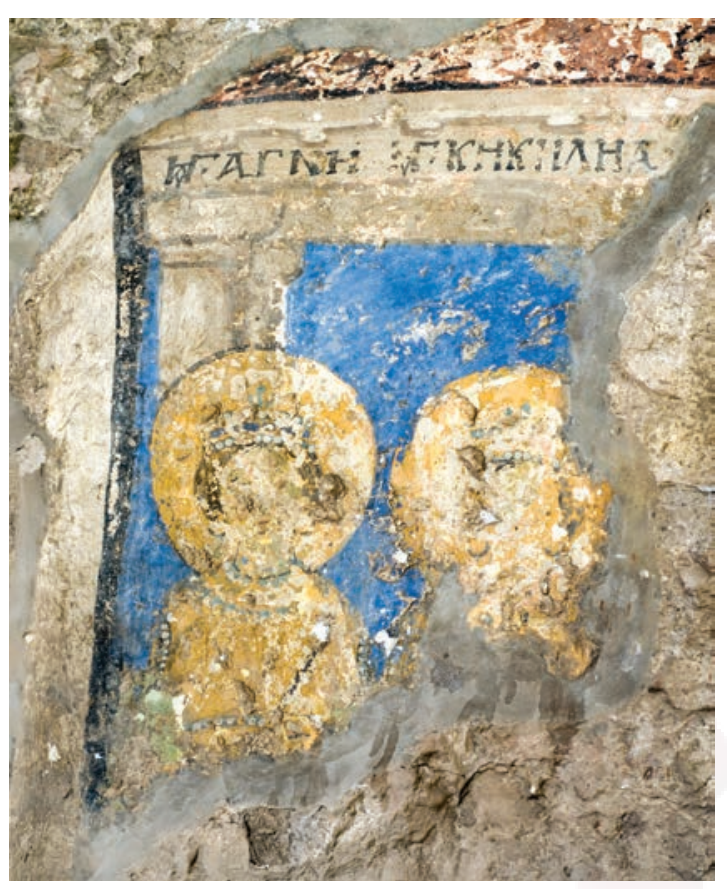

Fig. 19 S. Maria Antiqua, atrio, nicchia con le sante Agnese e Caterina (G. Alfano).

Fig. 20 S. Lorenzo fuori le mura, cappella "H9", parete est, sant'Eugenia (G. Bordi).

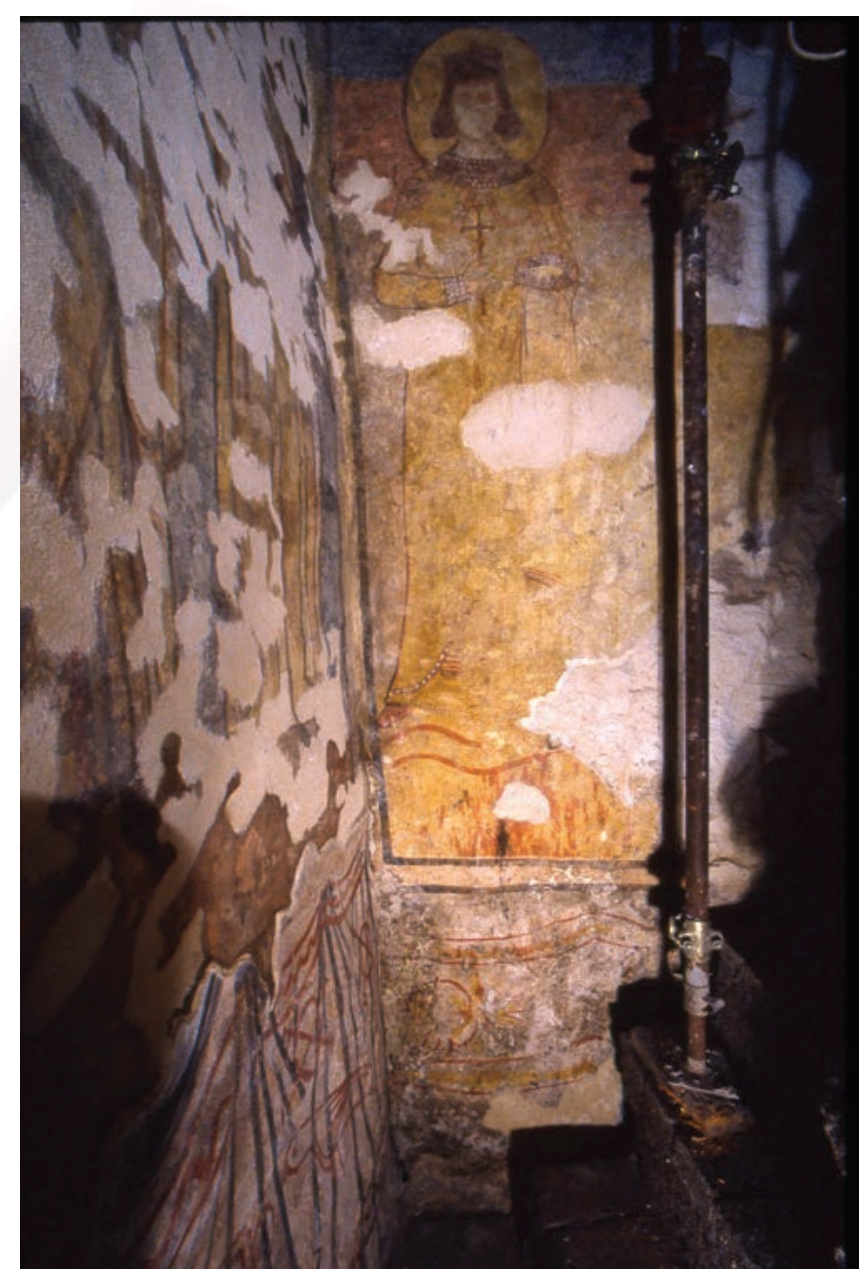




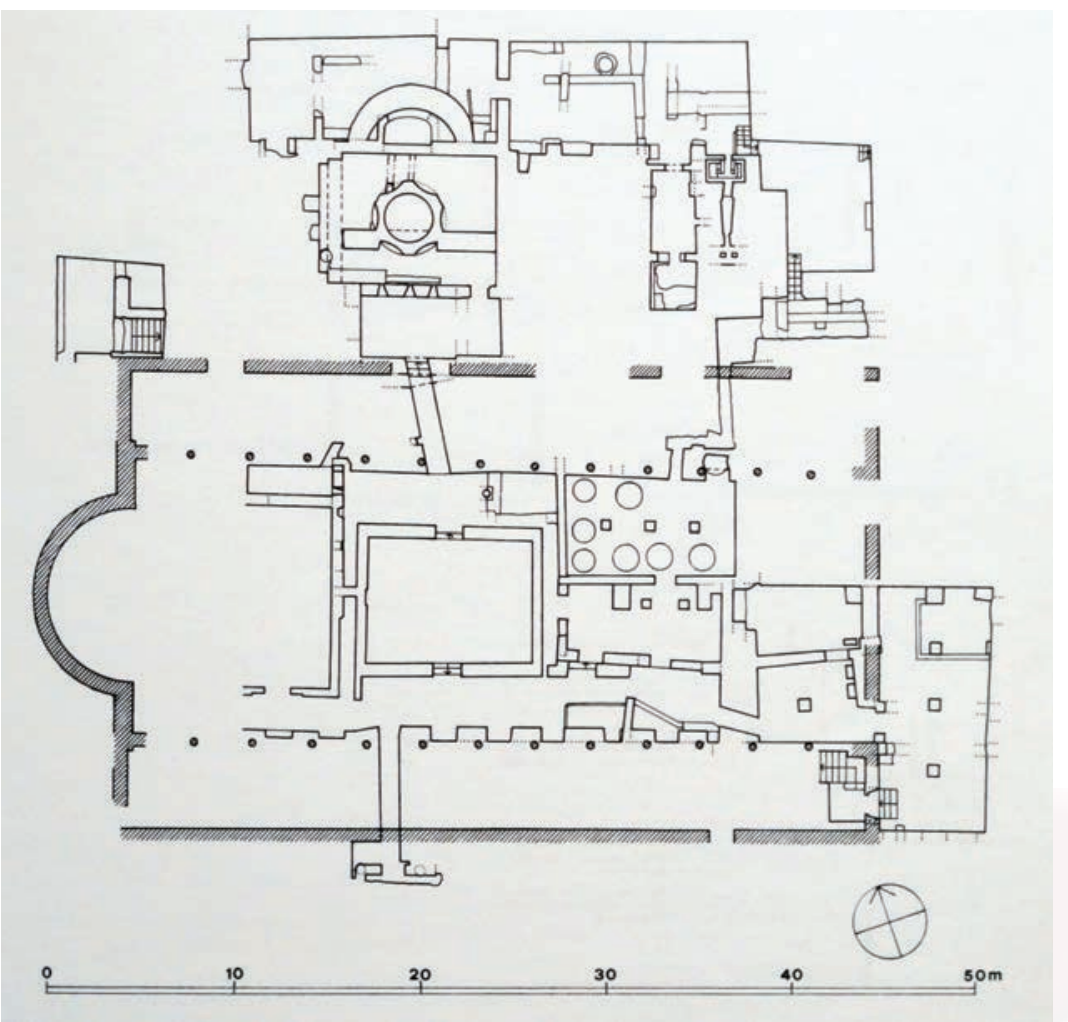

Fig. 21 Pianta dell'area archeologica di S. Cecilia in Trastevere (da Parmegiani, Pronti 2007a).

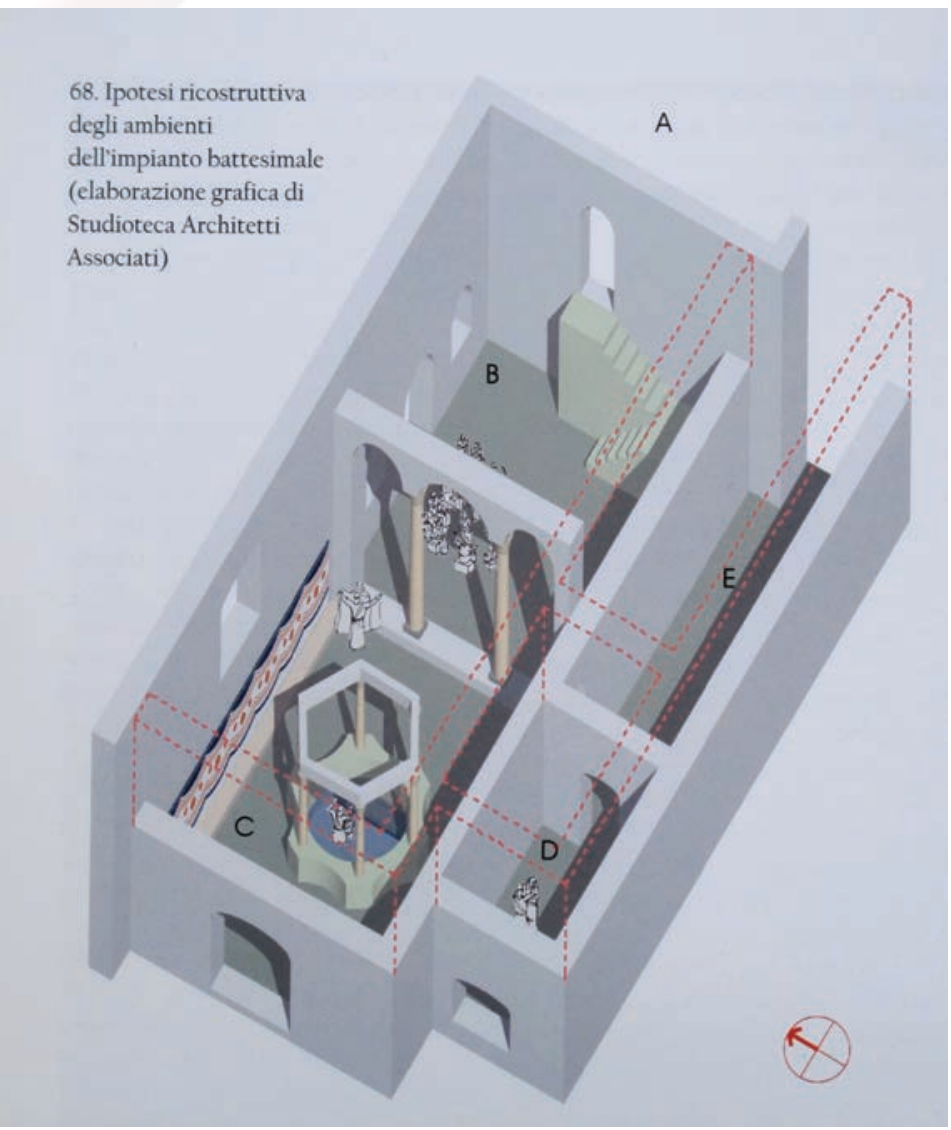




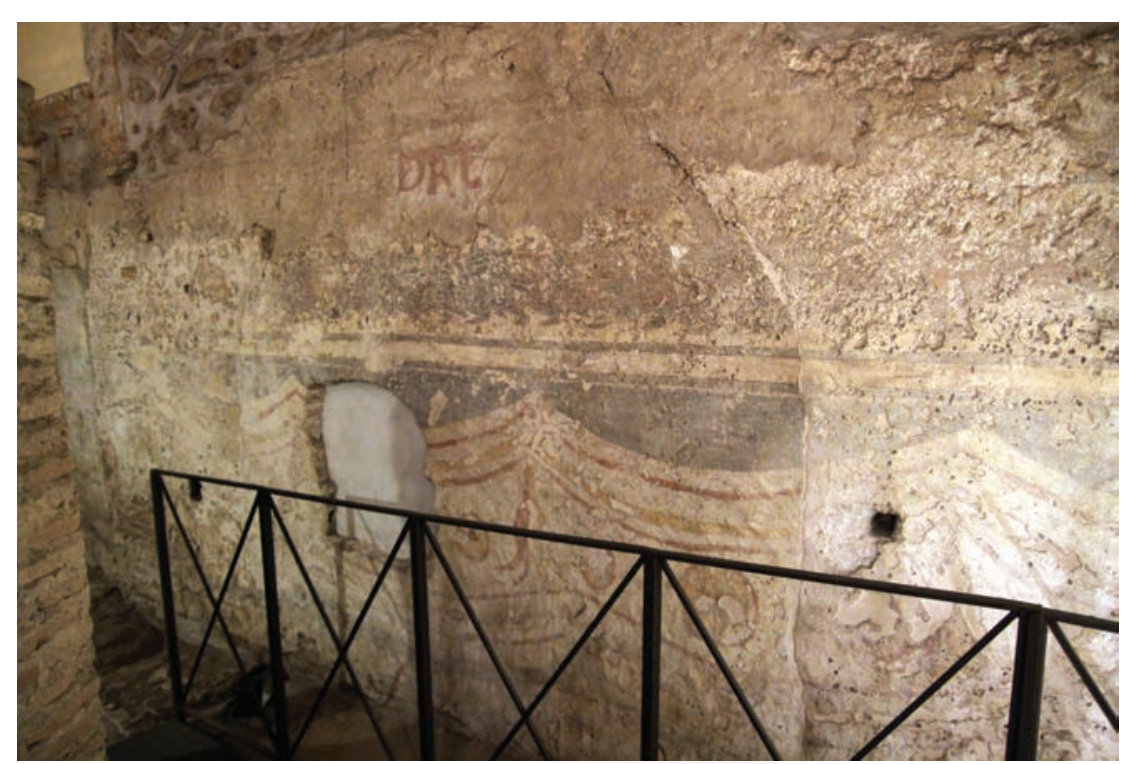

Fig. 23 S. Cecilia in Trastevere, Battistero, parete nord, velario dipinto (ArxiuCMancho)

Fig. 24 S. Cecilia in Trastevere, Battistero, parete nord, velario dipinto, particolare (G. Bordi)
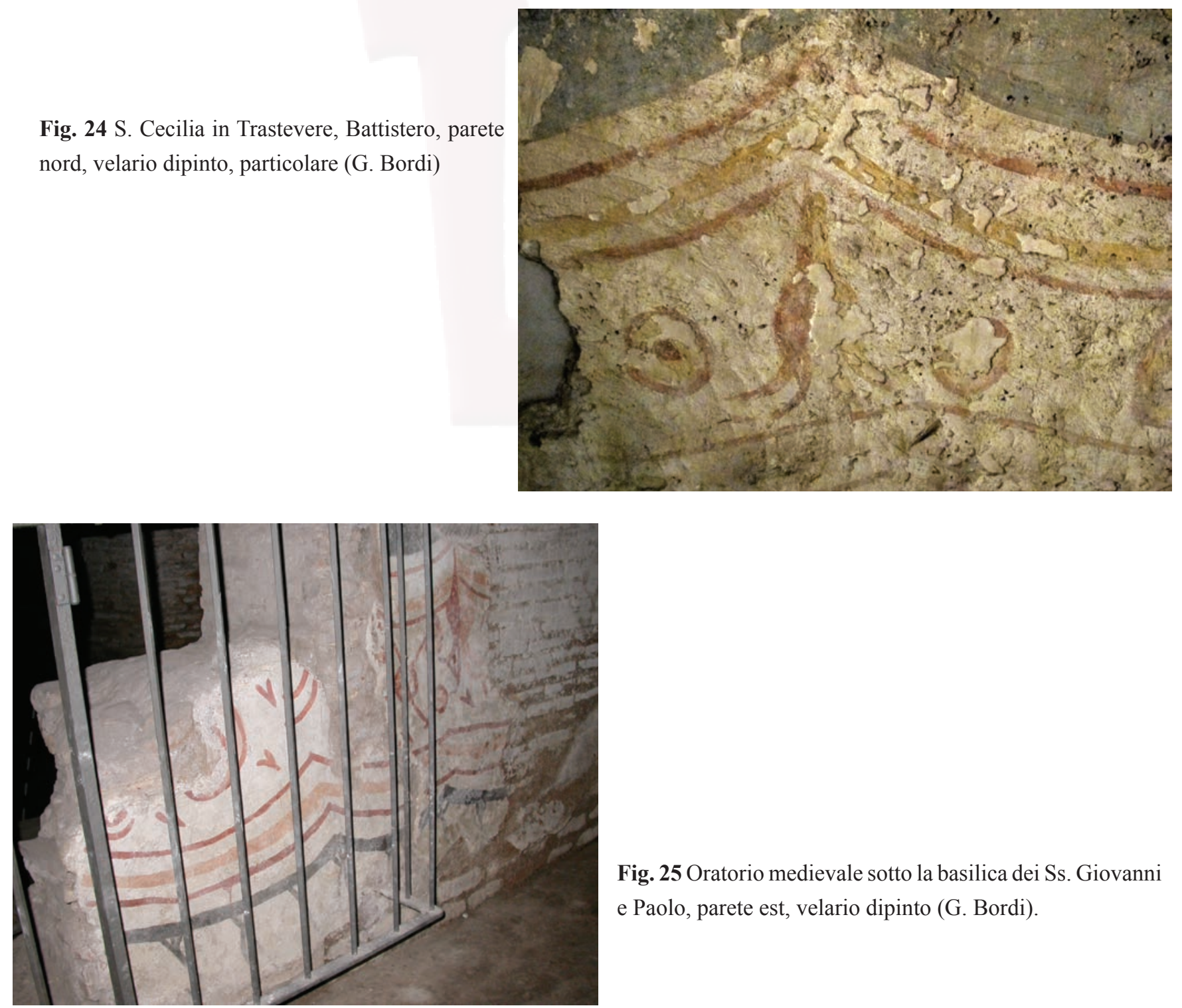

Fig. 25 Oratorio medievale sotto la basilica dei Ss. Giovanni e Paolo, parete est, velario dipinto (G. Bordi). 
Fig. 26 S. Lorenzo fuori le mura, cappella "H9", parete est, velario dipinto (G. Bordi).
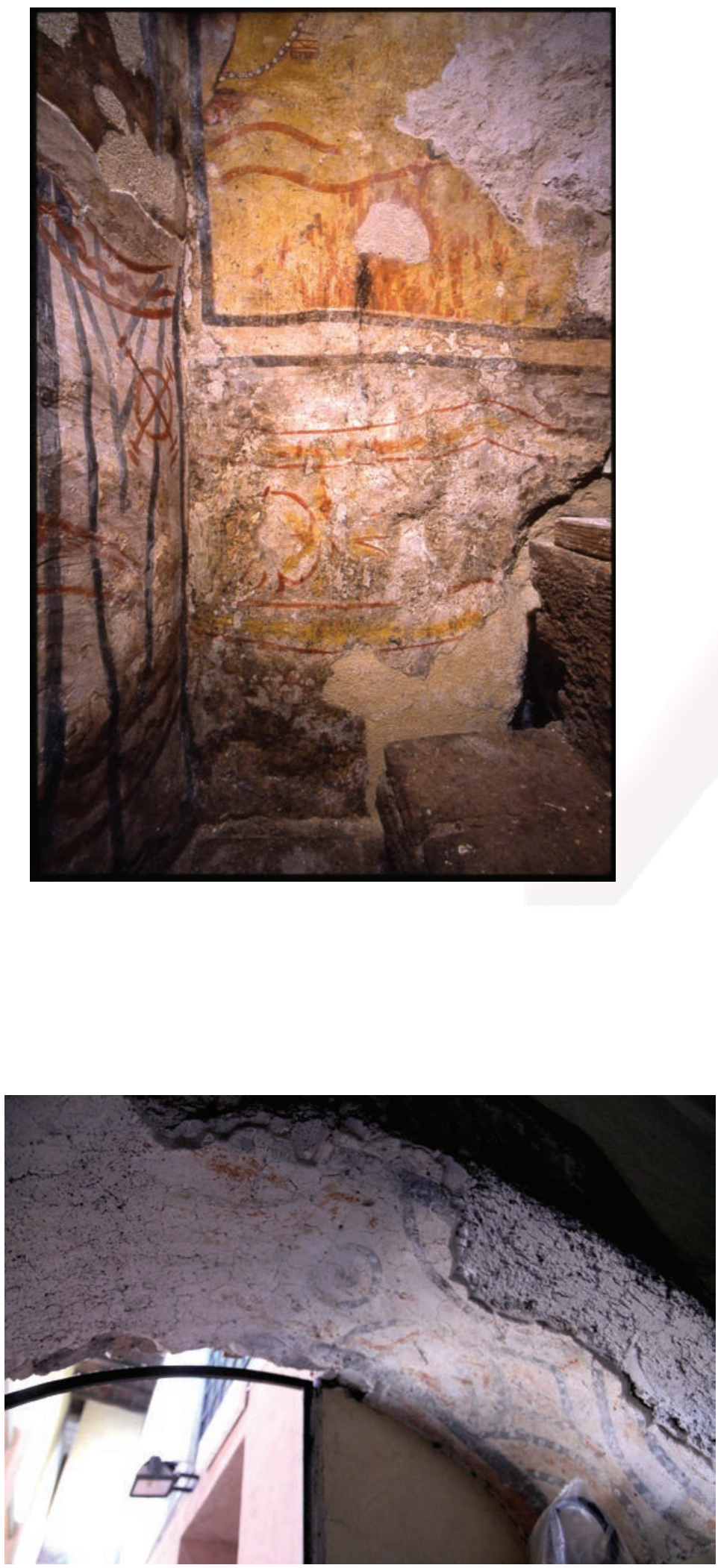

Fig. 28 S. Cecilia in Trastevere, Battistero, sottarco nord della "trifora" (ArxiuCMancho).
Fig. 27 S. Cecilia in Trastevere, Battistero, sottarco centrale della "trifora" (G. Bordi)

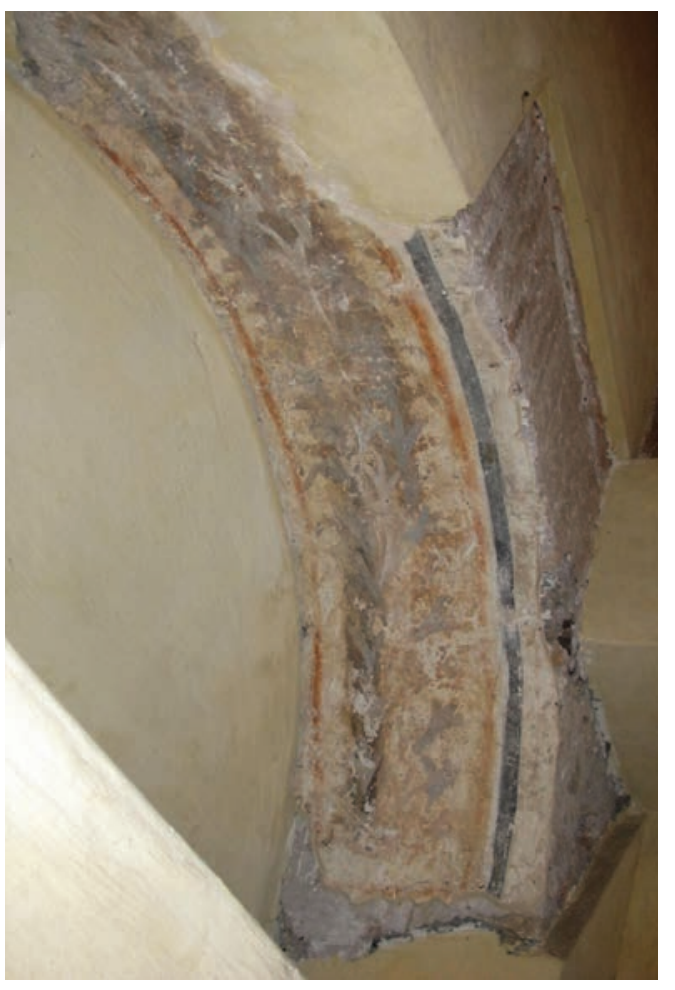


Fig. 29 S. Cecilia in Trastevere, Battistero, parete sud(ArxiuCMancho).

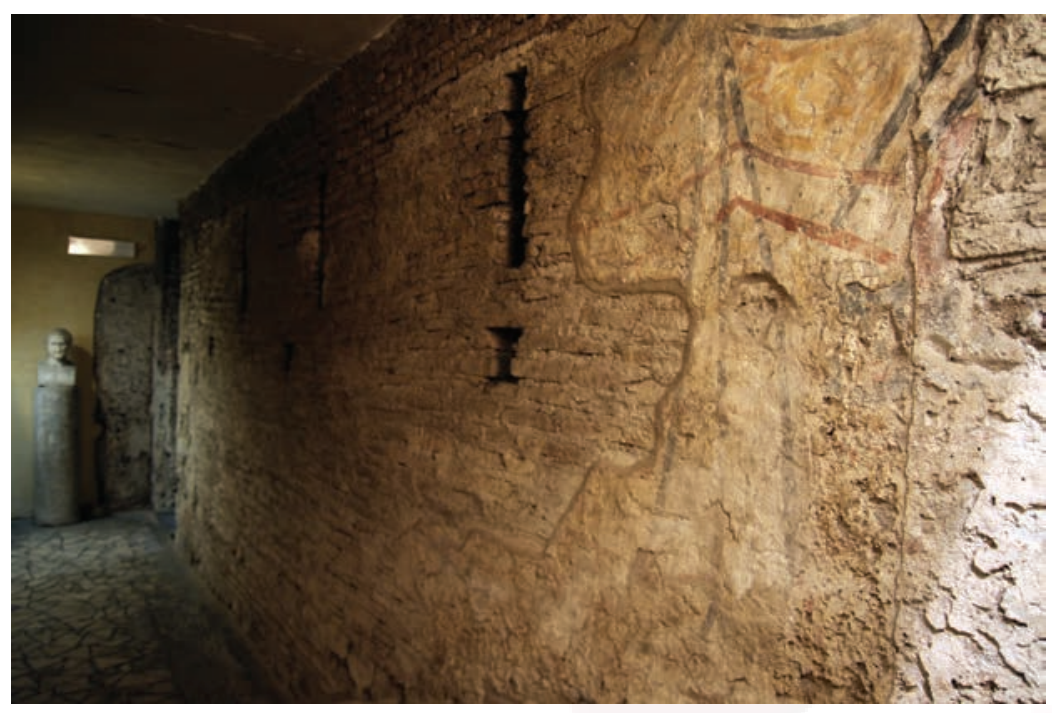

Fig. 31 Ss. Quirico e Giulitta, Chiesa inferiore, absidiola nord, velario dipinto (G. Bordi).

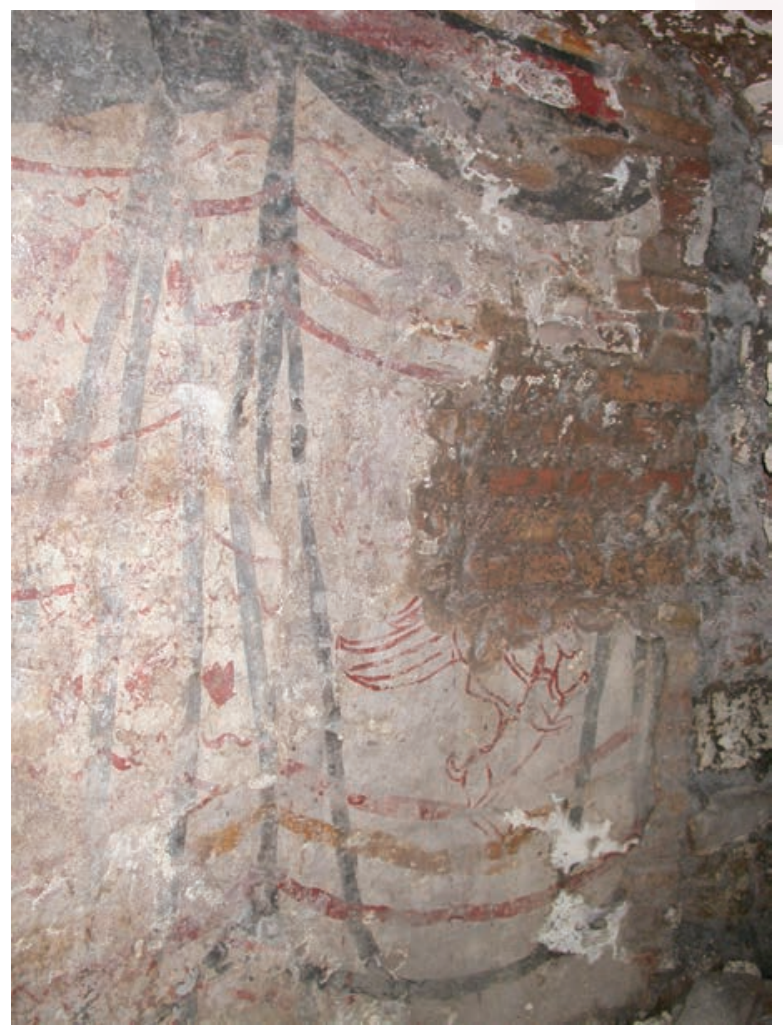

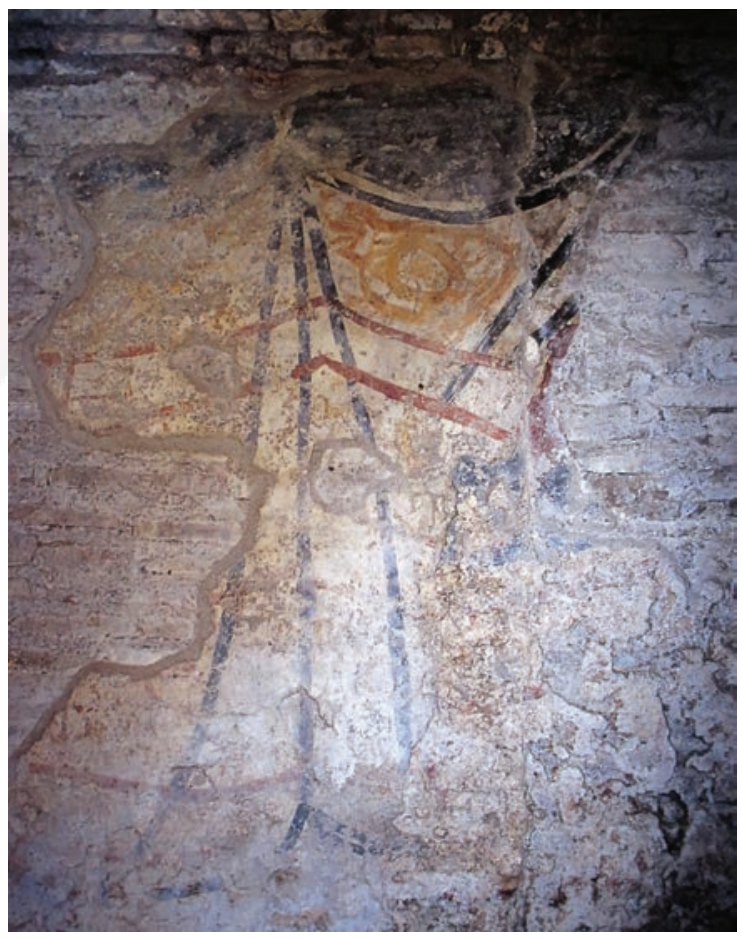

Fig. 30 S. Cecilia in Trastevere, Battistero, parete sud, velario dipinto (G. Bordi) 


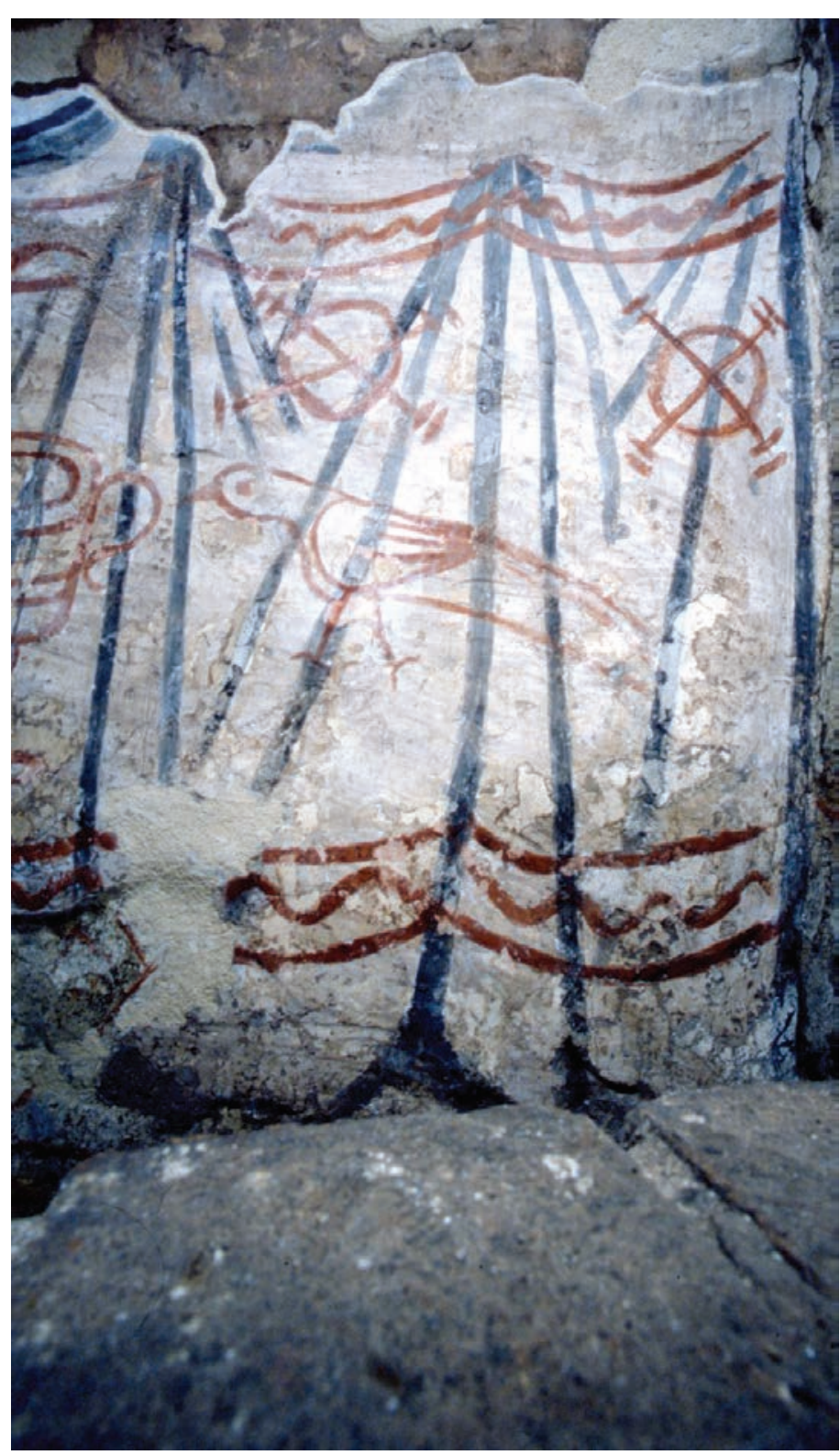

Fig. 32 S. Lorenzo fuori le mura, cappella "H9", parete nord, velario dipinto (R. Sigismondi). 